\title{
Aptitude technologique de différents coagulants du lait. Influence de la composition de leur "support"
}

\author{
P. GRANDAY *, B. MIETTON **, Aline OLSSON ***, \\ J.L. PERROD *, J.P. QUIBLIER ** \\ avec la collaboration technique de Dominique DUMOULIN **, \\ Y. GAUZERE ** et J. MILLET ** \\ * Laboratoire Présure GRANDAY, BP 3, 21201 Beaune, France \\ ** ENIL, BP 91, 39800 Poligny, France \\ *** ENITA, BP 48, 21800 Quetigny, France
}

\section{Résumé}

La standardisation des teneurs en enzymes actives (chymosine et pepsine bovine) des agents coagulants permet de mettre en évidence les effets liés à la nature et à la composition des liquides de dissolution de ces enzymes. Dans cette étude ont été arbitrairement distingués après séparation, par ultrafiltration sur membrane 10000 , les enzymes actives (rétentat) et l'ultrafiltrat que l'on peut qualifier du terme "support ".

Un examen systématique de différents agents coagulants actuellement proposés en fromagerie montre une très grande variation de la composition des « supports " notamment en ce qui concerne leurs teneurs en sel et en composés azotés. Cette variation a un effet significatif sur le comportement rhéologique des caillés, la cinétique de la synérèse et finalement sur le rendement fromager et la qualité des produits finaux. A titre indicatif, les essais réalisés en fromagerie de pâte molle (carrés de l'Est et pâte solubilisée) montrent que le coagulant Mucagel (enzyme de Mucor miehei et * support » de l'extrait de présure) conduit à une amélioration significative des paramètres fromagers par rapport au coagulant composé de l'enzyme de Mucor miehei et de son « support " habituel.

A partir de l'ensemble des résultats obtenus, il est proposé d'adapter le couple enzyme + «support» au type de fabrication fromagère envisagée.

Mots clés : Présure - Coagulant - Composition biochimique - Fabrication fromagère.

\section{Summary}

Technological ability of different milk coagulating agents.

Influence of the diluting liquid composition

Effect of nature of coagulating agent on cheesemaking parameters and on final charateristics of end products was studied. 
From a systematical survey of commercial coagulating agents containing rennet and fungal (Mucor miehei and Endothia parasitica) enzymes diluted in different solutions, it appears that the composition of the diluting enzyme liquid strongly varies in terms of salts and nitrogenous component contents. Such a variation has significant effect on the rheological behaviour of milk curds and their kinetics of syneresis. For example, during cheesemaking of soft cheeses, uses of a diluting liquid obtained by ultrafiltrating rennet extract can significantly improve cheese yielding capacity of the milk by Mucor miehei enzyme. Such results are correlated to the contents in mineral salts $(\mathrm{NaCl}$ and phosphate) and in organic nitrogen of this UF extract compared to those of usual diluting liquid of commercial Mucor miehei preparation.

Key words : Rennet - Coagulant - Biochemical composition - Cheesemaking.

\section{Introduction}

Consécutivement à l'adoption comme méthode officielle (J.O. du 20 mars 1981) de la technique de dosage proposée par les chercheurs des laboratoires I.N.R.A. de Rennes et de Poligny, l'ensemble des préparations commerciales de présure a maintenant des teneurs standardisées en chymosine et en pepsine bovine. De ce fait, les différences constatées en pratique fromagère lors de l'emploi d'agents coagulants de diverses origines, mais de même dénomination au niveau légal, ne peuvent avoir d'autres raisons que des variations de composition du liquide de dissolution des enzymes proprement dites. Ce liquide peut contenir des macromolécules elles-mêmes actives et présentes à l'état de traces (telles que lipases, lysozymes gastriques...), mais aussi des composés de plus faible poids moléculaire. Dans cette étude ont été arbitrairement distingués après séparation, par ultrafiltration sur membrane 10000 , les enzymes actives (rétentat) et l'ultrafitrat que l'on peut qualifier du terme « support».

Le rôle déterminant du «support » des enzymes coagulantes vis-à-vis de l'activité des levains lactiques ou de la production de flaveurs spécifiques est bien connu en fromagerie traditionnelle de Gruyère de Comté, de Beaufort ou de fromages italiens comme le Provolone ou ses dérivés (Garnier et al., 1968). Toutes les tentatives pour substituer des enzymes purifiées à ces présures dites «à la recuite » (fromagerie de pâtes pressées) ou « en pâte » (fromages italiens) ont conduit à des fromages de qualité inférieure.

Mais outre ces relations très spécifiques entre «support » et certains types de fabrications fromagères, les praticiens ont constaté, depuis longtemps, que les caractéristiques du « support » avaient une influence non négligeable sur les paramètres de toute transformation du lait en fromage : vitesse d'acidification rhéologie du coagulum - synérèse - rendement et qualités organoleptiques des produits finis. Leur prudence, notamment dans la substitution d'une forme d'agent coagulant à une autre, a pour base ces observations (GARNIER et al., 1968).

Sur un autre plan, ces mêmes observations ont conduit à la mise au point du coagulant "Mucagel » (GrandaY, 1980) constituant une nouvelle forme de présentation de l'enzyme extraite de Mucor miehei. La comparaison de ce nouveau coagulant avec la présentation classique de l'enzyme extraite de 
Mucor miehei a permis à MietTon et al. (1982) de démontrer des différences significatives en transformations fromagères tant au niveau de fabricationspilotes qu'au niveau industriel.

Aussi, nous a-t-il paru intéressant d'étudier la composition biochimique de différents « supports » entrant dans les préparations actuellement commercialisées de présure et d'enzymes fongiques, dans le but de préciser les relations existant entre la présence de leurs divers composants et les conséquences de l'emploi de ces "supports" en fromagerie de pâtes molles et d'emmental.

\section{Matériel et méthodes}

\section{A. Enzymes coagulantes utilisées}

Différentes préparations commerciales coagulantes provenant de 6 fournisseurs différents, numérotés de 1 à 6 , ont été collectées, à plusieurs reprises, entre 1982 et 1984 et étudiées. Il s'agissait de :

\section{Présures}

- 24 extraits de présure (EP) : teneur en chymosine supérieure ou égale à $520 \mathrm{mg} / \mathrm{l}$.

- 17 extraits de présure concentrés (EPC) : teneur en chymosine supérieure ou égale à $650 \mathrm{mg} / \mathrm{l}$.

\section{Préparations d'origine fongique}

- 7 préparations d'enzyme de Mucor miehei $(\mathrm{Mm})$, dont $\mathrm{Mm}_{1}$ (Mucagel marque déposée, brevet Granday et al., 1980).

- 2 préparations d'enzyme d'Endothia parasitica (ep).

Le nombre des préparations prélevées par fournisseur est indiqué au tableau 1.

De plus, une préparation expérimentale $\left(\mathrm{Mm}_{1}+\mathrm{S}_{1}\right)$ a été testée. Elle correspondait à la double addition de la préparation commerciale de Mucor miehei du fournisseur 1 et du «support $» \mathrm{~S}_{1}$ à la dose de $0,1 \%$ au lait lors de l'emprésurage.

\section{B. Déterminations analytiques}

Le «support » des préparations coagulantes était obtenu par ultrafiltration sur membrane d'esters de cellulose (Millipore PTGC 047 - seuil de coupure 10000 daltons - sous une pression de $5 \times 10^{5}$ Pascals).

Sur ces différents «supports " étaient déterminées :

- la teneur en chlorure par la méthode argentimétrique (CHARPENTIER et VOLHARD, 1874) ; 
TABLEAU I

Tableau récapitulatif des préparations coagulantes étudiées

Summary of the studied milk coagulants

\begin{tabular}{|c|c|c|c|}
\hline \multicolumn{2}{|c|}{ COAGULANTS } & $\begin{array}{l}\text { Code avec indice } \\
\text { fournisseur }\end{array}$ & $\begin{array}{c}\text { Nombre de préparations } \\
\text { prélevées }\end{array}$ \\
\hline \multirow{2}{*}{$\begin{array}{l}n \\
\omega \\
\simeq \\
D \\
n \\
w \\
\simeq \\
a\end{array}$} & $\begin{array}{l}\text { Extraits de présure } \\
\text { (EP) }\end{array}$ & $\begin{array}{l}\mathrm{EP}_{1} \\
\mathrm{EP}_{2} \\
\mathrm{EP}_{3} \\
\mathrm{EP}_{4}\end{array}$ & $\begin{array}{l}9 \\
6 \\
4 \\
5\end{array}$ \\
\hline & $\begin{array}{c}\text { Extraits de présure } \\
\text { concentrés } \\
\text { (EPC) }\end{array}$ & $\begin{array}{l}\mathrm{EPC}_{1} \\
\mathrm{EPC}_{2} \\
\mathrm{EPC}_{3}\end{array}$ & $\begin{array}{l}9 \\
6 \\
2\end{array}$ \\
\hline \multirow{2}{*}{ 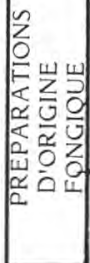 } & $\begin{array}{l}\left.\begin{array}{l}\text { Mucagel } \\
\text { Mucor miehei }\end{array}\right\}(\mathrm{Mm}) \\
\text { Endothia parasitica (ep) }\end{array}$ & $\begin{array}{l}\mathrm{Mm}_{1} \\
\mathrm{Mm}_{5} \\
\mathrm{ep}_{6}\end{array}$ & $\begin{array}{l}3 \\
4 \\
2\end{array}$ \\
\hline & Préparation expérimentale & $\mathrm{Mm}_{1}+\mathrm{S}_{1}(*)$ & 1 \\
\hline
\end{tabular}

(*): "support" de $M m_{1}$ apporté au lait lors de l'emprésurage à raison de 0,1\%

- la teneur en phosphate (exprimée en $\mathrm{P}_{2} \mathrm{O}_{5}$ ) par la réduction du complexe phosphomolybdique par l'acide ascorbique (DUVAL, 1963) ;

- les teneurs en azote : azote total par macrokjeldahl et azote ammoniacal par colorimétrie en présence de nitroprussiate de sodium (FLEURY et EBERRHARD, 1958).

L'étude qualitative de la fraction azotée a été réalisée par chromatographie sur colonne (hauteur : $1 \mathrm{~m}$; section : $4,9 \mathrm{~cm}^{2}$ ) remplie de gel Séphadex $\mathrm{G} 25$, maintenue dans une enceinte réfrigérée à $8^{\circ} \mathrm{C} \pm 1^{\circ} \mathrm{C}$.

L'éluant était une solution d'acétate de sodium à pH $6(0,05 \mathrm{M}$ acétate de sodium $+0,05 \mathrm{M} \mathrm{NaCl})$. Le débit d'élution était fixé à $40 \mathrm{ml} / \mathrm{h}$. La densité optique de l'éluat était déterminée en continu à l'aide d'un détecteur UV (ISCO UA 5) par enregistrement à $280 \mathrm{~nm}$ et après coloration à la ninhydrine à $570 \mathrm{~nm}$ selon la méthode de Moore et Stein.

Le volume d'exclusion ( $\mathrm{Ve}$ ) de la colonne était déterminé par passage d'une solution de bleu de dextran (PM : $2 \times 10^{6}$ ). Le poids moléculaire (PM) des différentes fractions isolées était approximativement évalué par étalonnage de la colonne de Séphadex G 25 à l'aide de molécules de poids moléculaires connus : 
- bacitracine (PM : 1450 ) ; Ve compris entre 260 et $290 \mathrm{ml}$;

- tyrosine (PM : 181) ; Ve compris entre 430 et $450 \mathrm{ml}$;

- benzoate de sodium (PM : 144); Ve compris entre 440 et $480 \mathrm{ml}$.

\section{Analyse du comportement rhéologique des laits emprésurés à l'aide des différentes préparations}

Le schéma expérimental retenu (tabl. 2) permettait de comparer l'effet de la nature des enzymes coagulantes et celui des "supports" sur les comportements rhéologiques des laits lors de leur coagulation.

\section{TABLEAU II}

Schéma expérimental de comparaison des préparations coagulantes Comparison scheme of coagulating preparations

\begin{tabular}{|c|c|c|}
\hline Variables & Points communs & Coagulants comparés \\
\hline $\begin{array}{c}\text { Nature des enzymes } \\
\text { coagulantes }\end{array}$ & "Support" identique & $\mathrm{EP}_{1} / \mathrm{Mm}_{1}$ \\
\hline Nature des "supports" & $\begin{array}{r}\text { Même activité } \\
\text { Enzyme identique } \\
\text { en chymosine }\end{array}$ & $\mathrm{Mm}_{1} / \mathrm{Mm}_{5}$ \\
\hline $\begin{array}{c}\text { Nature des enzymes } \\
\text { coagulantes + nature } \\
\text { des "supports" }\end{array}$ & Néant & $\mathrm{EPC}_{1} / \mathrm{EPC}_{3} / \mathrm{EP}_{4} /$ \\
\hline
\end{tabular}

Pour les présures, après détermination de leur teneur en chymosine selon la méthode officielle (J.O. du 20 mars 1981), les différentes préparations étaient ajustées à même teneur en chymosine par dilution dans leur propre «support» tout en gardant leur rapport respectif chymosine/pepsine. Pour les coagulants fongiques, l'ajustement était effectué de la même manière afin d'obtenir un même temps de floculation sur substrat de Berridge modifié (J.O. du 20 mars 1981).

L'évolution en fonction du temps, des caractéristiques rhéologiques des laits emprésurés, était suivie à l'aide du Gelograph (Gel Instrument, Suisse).

Cette étude était conduite sur le lait reconstitué (poudre de lait écrémé « basse température " reconstituée à $90 \mathrm{~g} / 1$ d'extrait sec total, additionnée de $0,1 \mathrm{~g} / \mathrm{l}$ de $\mathrm{CaCl}_{2}$ anhydre) à $20^{\circ} \mathrm{C}$.

Pour les extraits de présure et les préparations à base de $\mathrm{Mm}$, le $\mathrm{pH}$ et la température à l'emprésurage étaient respectivement de 6,60 et $35^{\circ} \mathrm{C}$, pour obtenir un temps de floculation de 10 à $12 \mathrm{mn}$. 
Pour les extraits de présure concentrés et les préparations à base d'ep, le $\mathrm{pH}$ et la température à l'emprésurage étaient de 6,65 et $31^{\circ} \mathrm{C}$, pour obtenir un temps de floculation de 20 à $25 \mathrm{~min}$.

Les mesures rhéologiques étaient également conduites sur le lait de fabrication de fromage d'emmental, en parallèle au travail en cuve, afin de vérifier l'adaptation du fromager aux comportements spécifiques des coagulants (décaillage à même fermeté).

Les paramètres rhéologiques relevés sur les rhéogrammes étaient :

- le temps de floculation $=r$, exprimé en $s$;

- le temps pour obtenir une fermeté standard de $10 \mathrm{mPas}=\mathrm{k} 10$ ou 100 $\mathrm{mPas}=\mathrm{k} 100$;

- la fermeté du gel après un temps de durcissement équivalent soit à : $1 / 2$ fois, 1 fois, 2 fois le temps de floculation : a0,5r; ar ; $a 2 r$.

La cinétique d'organisation des gels était appréciée par le calcul des rapports $\frac{\mathrm{k} 10}{\mathrm{r}}$ et $\frac{\mathrm{k} 100}{\mathrm{r}}$.

\section{Fabrications fromagères expérimentales}

Pour les fabrications fromagères, trois technologies étaient mises en cuvre :

— pâte molle : carré de l'Est ;

- pâte molle type solubilisé ;

- pâte pressée cuite : emmental au lait cru.

Le schéma expérimental retenu (tabl. 3) permettait de comparer l'effet de la nature des enzymes coagulantes, de la nature du «support», de la dose de "support » sur les comportements rhéologiques des laits et leurs incidences sur les fabrications.

\section{Schémas technologiques}

Pour les pâtes molles, les schémas technologiques utilisés étaient ceux décrits par Mietton et al. (1982). Du lait pasteurisé à $72{ }^{\circ} \mathrm{C}, 20 \mathrm{~s}$, était prématuré à $\mathrm{J}-1$, à $12-13^{\circ} \mathrm{C}$ pendant $16-18 \mathrm{~h}$, après ensemencement avec $0,2 \%$ de levain mésophile (Flora Danica) et addition de $0,05 \mathrm{~g} / 1 \mathrm{de} \mathrm{CaCl}_{2}$ anhydre. A Jo, le lait était thermisé à $65^{\circ} \mathrm{C}$ pendant $20 \mathrm{~s}$ et inoculé :

- pour les fabrications de carré de l'Est, avec $1,5 \%$ de levains mésophiles (Flora Danica) et maintenu à $35^{\circ} \mathrm{C}$ pendant $30 \mathrm{mn}$, afin d'obtenir à l'emprésurage un $\mathrm{pH}$ de 6,40-6,45;

- pour les pâtes molles solubilisées, avec $2 \%$ de levains streptocoques thermophiles (Lacto- Labo ST $10 \mathrm{~A}$ lot 128 ) et maitnenu à $37^{\circ} \mathrm{C}$ pendant 30 $\mathrm{mn}$, afin d'obtenir à l'emprésurage un $\mathrm{pH}$ de $6,40-6,45$. 
TABlEAU III

Plan expérimental des fabrications fromagères

* $M m_{1}+S_{1}$ : ajout de $100 \mathrm{ml}$ de «support» $S_{1}$ pour $100 \mathrm{l}$ de lait, soit 4 fois la dose d'emprésurage

Experimental method for cheesemaking studies

* $M m_{1}+S_{1}$ : addition of $100 \mathrm{ml}$ 《diluting solution " $S_{1}$ for $100 \mathrm{l}$ milk i.e.

4 times the rennet dose

\begin{tabular}{|c|c|c|c|c|c|}
\hline & \multicolumn{4}{|c|}{ Pâtes molles } & \multirow{3}{*}{$\begin{array}{c}\begin{array}{c}\text { Pâtes } \\
\text { pressées } \\
\text { cuites }\end{array} \\
\text { Emmental } \\
\text { Série E }\end{array}$} \\
\hline & \multirow{2}{*}{$\begin{array}{c}\begin{array}{c}\text { Carré de } \\
\text { l'Est }\end{array} \\
\text { Série A }\end{array}$} & \multicolumn{3}{|c|}{ Pâtes solubilisées } & \\
\hline & & Série B & Série C & Série D & \\
\hline$E P_{1}$ & & $\star$ & $\star$ & $\star$ & \\
\hline $\mathrm{EP}_{2}$ & & & & $\star$ & \\
\hline $\mathrm{EP}_{3}$ & & & & $\star$ & \\
\hline $\mathrm{EP}_{4}$ & & & & $\star$ & \\
\hline $\mathrm{EPC}_{1}$ & $\star$ & & & $\star$ & $\star$ \\
\hline $\mathrm{EPC}_{2}$ & & & & & $\star$ \\
\hline $\mathrm{Mm}_{1}$ & $\star$ & $\star$ & $\star$ & & \\
\hline $\mathrm{Mm}_{5}$ & $\star$ & $\star$ & $\star$ & & \\
\hline$M m_{1}+S_{1} \quad(*)$ & & $\star$ & $\star$ & & \\
\hline $\mathrm{ep}_{6}$ & & & & & $\star$ \\
\hline $\begin{array}{l}\text { Nombre de } \\
\text { répétitions }\end{array}$ & 3 & 3 & 3 & 3 & 6 \\
\hline $\begin{array}{r}\text { Nombre de } \\
\text { fabrications }\end{array}$ & 9 & 12 & 12 & 15 & 18 \\
\hline
\end{tabular}

(*): "support" de $M m_{1}$ apporté au lait lors de l'emprésurage à raison de 0,1\%

Des bassines contenant 50 litres de lait étaient emprésurées en parallèle avec différentes préparations coagulantes suivant une permutation circulaire lors des répétitions. L'emprésurage était effectué sur une base de $25 \mathrm{ml}$ d'extrait de présure par $100 \mathrm{l}$ de lait, soit $13 \mathrm{mg}$ de chymosine par 1001 . Après détermination des teneurs en chymosine, la dose de présure était modulée afin d'apporter la même quantié de chymosine dans tous les essais. Les différentes présures conservaient leur rapport chymosine/pepsine originel.

La dose d'emprésurage des essais utilisant des coagulants fongiques était calculée afin d'obtenir un même temps de floculation sur substrat de Berridge modifié.

Les fromages obtenus avaient un format carré de $10 \mathrm{~cm}$ de côté pour une hauteur de $3,5 \mathrm{~cm}$. Leur poids moyen était de $280 \mathrm{~g}$. Ils étaient affinés pendant 9 jours à $12{ }^{\circ} \mathrm{C}$ et $90 \%-95 \%$ d'hygrométrie relative (HR), emballés à 
$\mathrm{J}+10$ dans un complexe aluminium et conservés à $4{ }^{\circ} \mathrm{C}$ et $7{ }^{\circ} \mathrm{C}$ pour estimer l'aptitude au vieillissement.

La cinétique de l'égouttage en moule était suivie par pesée du caillé dans son multimoule, immédiatement après les retournements qui étaient effectués $30 \mathrm{mn}, 3 \mathrm{~h}, 6 \mathrm{~h}$ et $8 \mathrm{~h}$ après moulage.

- Les fabrications d'emmental étaient réalisées à partir de lait cru, en cuves traditionnelles de 500 litres, en utilisant un équipement de soutirage sous-vide donnant des meules d'un poids voisin de $42 \mathrm{~kg}$.

\section{Estimation de l'affinage}

La protéolyse des fromages et sérums d'emmental au démoulage était déterminée par le dosage des matières azotées solubles (NS) à $\mathrm{pH}=4,6$ et de l'azote non protéique (NNP) soluble dans l'acide trichloracétique à $12 \%$ par macrokjeldahl. Le niveau de protéolyse était apprécié par les rapports des matières azotées solubles sur les matières azotées totales (NS/Nt) et des matières azotées non protéiques sur les matières azotées totales (NNP/Nt).

Pour les fabrications d'emmental, la mesure du point de congélation du filtrat de composés solubles dans l'eau était effectuée avec un cryoscope (Funk Gerber), selon le protocole I.T.G. (1985); la valeur de l'indice d'affinage étant égale à la valeur absolue du point de congélation mesuré.

Pour ces mêmes fabrications, la force d'extrusion était déterminée à l'aide d'un «Fira-Nird Extrudeur » selon le protocole I.T.G. (1984).

La vitesse de formation de l'ouverture des emmentals était estimée en relevant, sur les photographies des fromages prises à la coupe, les rapports hauteur sur largeur, ramenés au nombre de jours passés en cave chaude.

\section{Analyse sensorielle}

Les caractéristiques organoleptiques des échantillons anonymes de pâte molle étaient jugées individuellement par 3 ou 4 experts après 20 jours d'affinage, puis tous les 10 jours, jusqu'à 50 jours. Les jugements portaient sur la fleur, la coupe, la texture et la flaveur, notées en fonction d'une grille (Mietton, 1981).

Les caractéristiques organoleptiques des emmentals étaient notées après un mois de stockage en cave froide par un jury de 8 à 9 experts suivant la grille I.T.G. : la forme, le croûtage, l'ouverture, la pâte et la flaveur étaient notés sur les fromages coupés (I.T.G., 1978-1980). De plus, il était demandé aux mêmes experts de noter à nouveau comparativement la texture et la flaveur de chaque fromage sur les échantillons réduits en cubes.

\section{Rendement}

Les rendements fromagers, pour chaque type de fabrication, étaient déterminés pour $100 \mathrm{~kg}$ de lait mis en œuvre,

- au démoulage pour l'emmental ;

- après salage $(J+2)$ et après emballage $(J+10)$ pour les pâtes molles. 
Les rendements étaient corrigés selon Maubors et MocQuot (1967), afin de pouvoir comparer les rendements de fromages à même extrait sec total.

Les coefficients de récupération de la matière grasse, de la matière azotée protéique et de l'extrait sec total dans le fromage de 24 heures étaient mesurés par rapport aux quantités mises en œuvre dans le lait.

\section{E. Exploitation statistique des résultats}

Elle a été réalisée à l'aide du logiciel «STAT-ITCF » du service d'étude statistique et informatique de l'ITCF, 91700 Boigneville Maisse.

La variabilité de la composition biochimique des différents «supports» était appréciée pour chaque fournisseur et pour chaque type de préparations coagulantes, par le calcul des coefficients de variation (CV\%).

Les différences constatées entre «supports » étaient analysées par une méthode de comparaison de moyennes (petits échantillons indépendants).

L'incidence de la nature de l'enzyme ou du «support » sur les caractéristiques rhéologiques des laits emprésurés était estimée par analyse de variance. Le test de Newman Keuls a permis de comparer les moyennes des différents niveaux au seuil de $\alpha=0,05$. L'explication des variations par le facteur étudié était calculée par la somme des carrés des écarts du facteur, divisée par la somme des carrés des écarts de la variation totale multiplié par 100.

En ce qui concerne les fabrications fromagères, pour chaque répétition, les différentes préparations coagulantes étaient utilisées en parallèle dans des conditions rigoureusement identiques. Les différences observées liées aux coagulants étaient analysées en les comparant deux à deux selon leurs écarts mesurés à chaque répétition (comparaison des moyennes, méthode des couples).

\section{Résultats}

\section{A. Composition biochimique}

Les résultats moyens de la composition biochimique des « supports » sont présentés au tableau 4.

a) Selon le fournisseur, des différences de composition apparaissaient entre les préparations coagulantes d'origine animale étudiées :

- la teneur moyenne en $\mathrm{NaCl}$ variait de 133 à $206 \mathrm{~g} / \mathrm{l}$. Les écarts de teneur en sel des «supports » des différents fournisseurs étaient hautement significatifs $(\alpha=0,01)$ sauf entre $\mathrm{EP}_{3}$ et $\mathrm{EP}_{4}$;

- la teneur moyenne en $\mathrm{P}_{2} \mathrm{O}_{5}$ variait de 2 à $11 \mathrm{~g} / \mathrm{l}$, avec, à la différence du $\mathrm{NaCl}$, une forte dispersion des teneurs pour un même fournisseur. 


\section{TABLEAU IV}

Composition biochimique moyenne des "supports " des préparations coagulantes étudiées

Average biochemical composition of "diluting solutions" of coagulant preparations

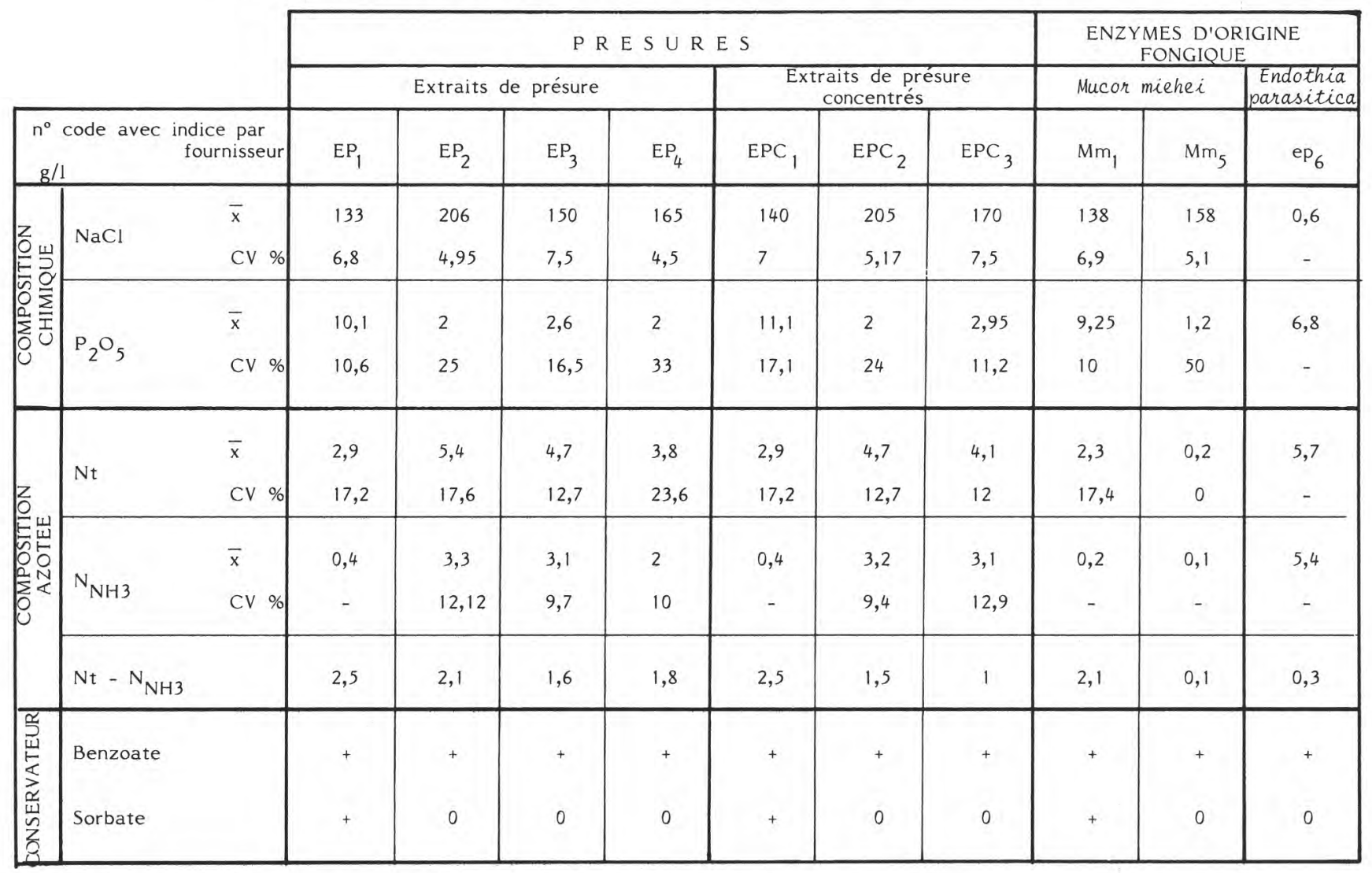

$\bar{x} \quad \vdots$ teneur moyenne

CV \% : coefficient de variation en $\%$ 
Le « support » des préparations coagulantes du fournisseur $\mathrm{n}^{\circ} 1$ présentait une tencur en $\mathrm{P}_{2} \mathrm{O}_{5}$ significativement supérieure $(\alpha=0,01)$ à l'ensemble des autres préparations. Aucune différence significative n'était notée entre les fournisseurs 2,3 et 4 ;

- la teneur moyenne en azote total $(\mathrm{Nt})$ variait de 2,9 à $5,4 \mathrm{~g} / \mathrm{l}$.

Les « supports » des présures du fournisseur $n^{\circ} 2$ avaient des teneurs en azote total significativement supérieures $(\alpha=0,05)$ aux préparations des fournisseurs 1,3 et 4 .

Les «supports» des présures du fournisseur $n^{\circ} 1$ avaient, quant à elles, des teneurs significativement inférieures $(\alpha=0,05)$ à celles des fabricants 2,3 et 4. Aucune différence significative n'était observée entre les «supports» des extraits de présure des fournisseurs 3 et 4 ;

- les teneurs moyennes en azote ammoniacal $\left(\mathrm{N}_{\mathrm{NH} 3}\right)$ variaient entre 0,4 et $3,3 \mathrm{~g} / 1$;

- la teneur en azote non ammoniacal, quantifiée par la différence entre azote total et azote ammoniacal $\left(\mathrm{Nt}-\mathrm{N}_{\mathrm{NH} 3}\right.$ ) permettait de différencier certains fournisseurs. Les "supports» des extraits de présure des fournisseurs 1 et 2 avaient des teneurs en azote non ammoniacal significativement supérieures $(\alpha=0,05)$ à celles des fournisseurs 3 et 4 .

En ce qui concerne les extraits de présure concentrés, la teneur en azote non ammoniacal du «support » du fabricant $\mathrm{n}^{\circ} 1$ était significativement plus élevée $(\alpha=0,05)$ que celle des «supports » des fabricants $n^{\text {os }} 3$ et 4 .

b) Les préparations coagulantes d'origine fongique présentaient des particularités : $\mathrm{NaCl}$;

- la préparation d'enzyme d'Endothia parasitica $\mathrm{ep}_{6}$ contenait peu de

- la préparation d'enzyme de Mucor miehei $\mathrm{Mm}_{5}$ se différenciait significativement $(\alpha=0,05)$ de la préparation $\mathrm{Mm}_{1}$ par des teneurs plus faibles en azote non ammoniacal et en $\mathrm{P}_{2} \mathrm{O}_{5}$.

c) Pour l'ensemble des préparations coagulantes, le benzoate de sodium était utilisé comme conservateur. Les «supports » du fournisseur $\mathrm{n}^{\circ} 1$ renfermaient aussi du sorbate de potassium. Celui du fournisseur $\mathrm{n}^{\circ} 6(\mathrm{ep})$ contenait $6 \mathrm{~g} / 1$ de sorbitol (selon le fournisseur).

d) L'étude comparée des profils chromatographiques obtenus sur gel Séphadex G 25 (fig. 1) permettait de constater que les différences observées n'étaient pas imputables à la préparation coagulante (EP, EPC, coagulants fongiques), mais étaient caractéristiques du fournisseur (même profil d'élution pour un fournisseur donné, quelque soit la préparation coagulante).

Les chromatogrammes ont été découpés arbitrairement en 4 fractions :

$-1^{\text {re }}$ fraction : composé a) de $1300<\mathrm{PM}<5000$; absorbant fortement après coloration à la ninhydrine et faiblement dans l'ultra-violet ;

$-2^{\mathrm{e}}$ fraction : composé b) de $200<\mathrm{PM}<1300$; absorbant à la fois dans l'ultra-violet et après coloration à la ninhydrine ;

$-3^{\mathrm{e}}$ fraction : composé c) de $100<\mathrm{PM}<200$;

$-4^{\text {e }}$ fraction : composés d) retardés à l'élution. 

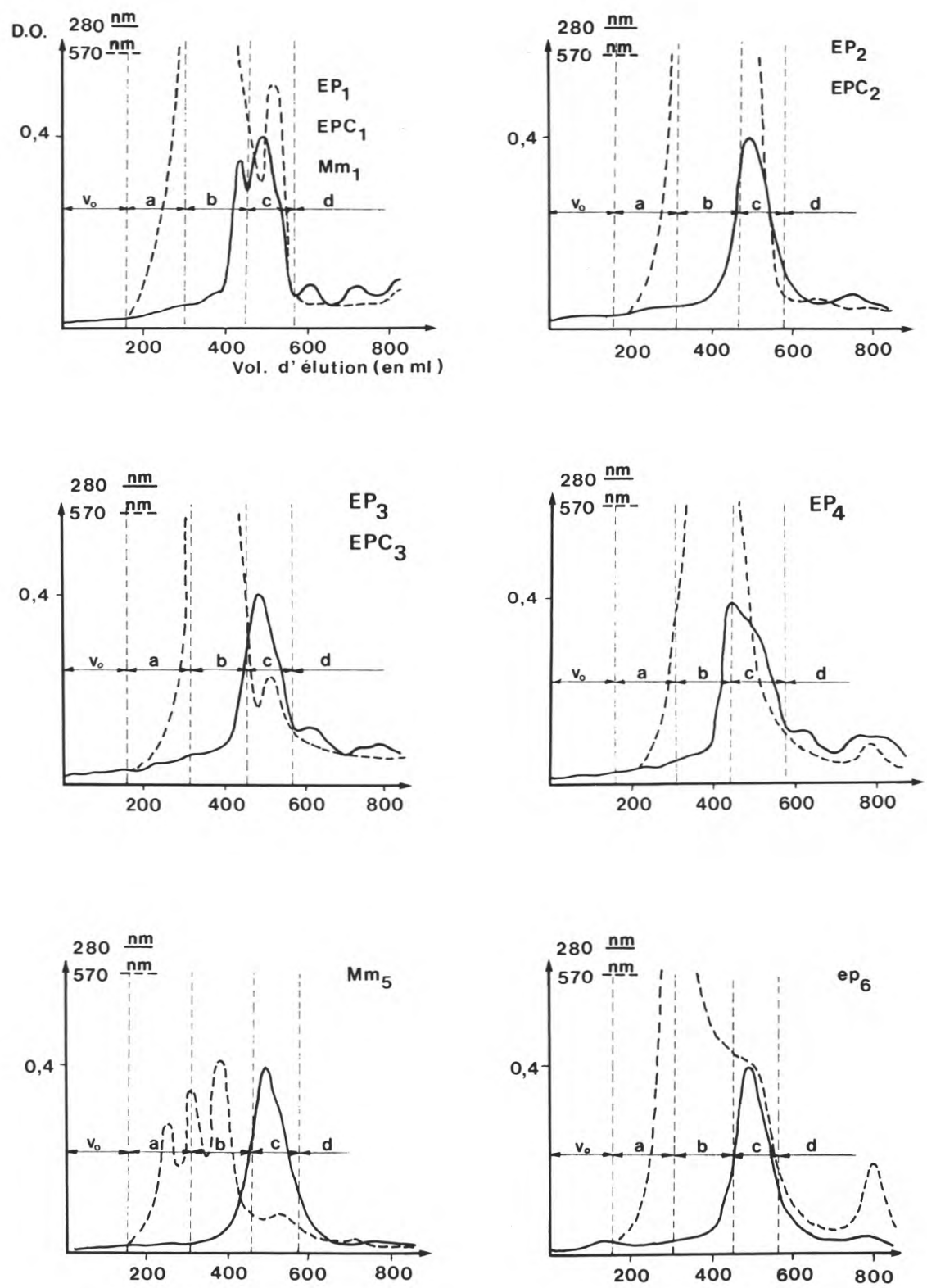

Fig. 1

Profils chromatographiques sur gel Séphadex G 25 obtenus avec différents "supports " des préparations coagulantes des différents fabricants.

Chromatogramms on Sephadex $G 25$ obtained with different diluting solutions of coagulant from different producers. 
Les chromatogrammes d'absorption à $280 \mathrm{~nm}$ et $570 \mathrm{~nm}$ de toutes les préparations de chacun des fournisseurs sont présentés figure 1. Aucune de ces préparations ne contenait de composé de PM $>5000$ (absence de pic d'exclusion). Le composé a $(1300<\mathrm{PM}<5000)$ était identique chez les fournisseurs $1,2,3,4$ et 6 . La méthode des ajouts permettait d'identifier le pic d'absorption c $(100<\mathrm{PM}<200)$ à $280 \mathrm{~nm}$, présent dans tous les profils comme correspondant au moins en partie au benzoate de sodium. Les «supports » du fabricant $\mathrm{n}^{\circ} 1$ présentaient toutefois un pic d'absorption supplémentaire à $280 \mathrm{~nm}$ de poids moléculaire supérieur, ce qui permettait la différenciation avec les profils caractéristiques du fournisseur $\mathrm{n}^{\circ} 3$. Les profils d'absorption à $570 \mathrm{~nm}$ permettaient quant à eux, la nette différenciation entre les «supports » des autres fournisseurs (nombre et emplacement des pics).

\section{B. Caractéristiques rhéologiques}

\section{Rôle de la nature de l'enzyme}

Une synthèse des résultats de l'analyse statistique de la variance est présentée dans le tableau $4^{\text {bis }}$.

L'enzyme de Mucor miehei $\mathrm{Mm}_{1}$ engendrait des profils rhéologiques différents de ceux obtenus avec l'extrait de présure $\mathrm{EP}_{1}$. Le temps pour obtenir une fermeté standard de 10 ou $100 \mathrm{mPas}$ était significativement $(\alpha=0,001)$ plus élevé et, après un temps de durcissement équivalent à 1 fois et 2 fois le temps de floculation (ar, a2r), les caillés obtenus à l'aide de l'extrait de présure $E_{1}$ étaient plus fermes (fig. 2).

Ces deux échantillons provenant d'un même fournisseur et possédant un " support » identique, les différences enregistrées étaient uniquement imputables à la nature de l'enzyme. L'analyse statistique des résultats obtenus montre que la nature de l'enzyme expliquait respectivement $68 \%$ et $98 \%$ de la vitesse d'organisation des caillés ( $\mathrm{k} 10 / \mathrm{r}, \mathrm{k} \mathrm{100/r}$ ); et $97 \%$ et $92 \%$ de la fermeté des gels à une fois et deux fois le temps de floculation.

Le comportement particulier d'Endothia parasitica ep $_{6}$ comparé à l'extrait de présure concentré $\mathrm{EPC}_{1}$ (fig. 3) était dû au double effet enzyme + « support ». Il se caractérisait par une cinétique d'organisation du caillé plus rapide :

- le temps pour obtenir une fermeté standard de $100 \mathrm{mPas}$ (k 100) était significativement plus faible $(\alpha=0,05)$ pour $\mathrm{ep}_{6}$;

- pour un même temps de floculation, la fermeté du coagulum après un durcissement équivalent à 0,5 fois le temps de floculation ou une fois le temps de floculation (a0,5r; ar) était significativement plus élevée $(\alpha=0,05)$.

Le facteur nature de l'enzyme coagulante expliquait respectivement $63 \%$ des variations de $\mathrm{k} 100,60 \%$ et $72 \%$ des variations de $\mathrm{a} 0,5 \mathrm{r}$ et ar.

\section{Rôle du support}

Les résultats sont consignés aux tableaux 5,6 et 7 . Des différences apparaissaient entre plusieurs préparations contenant une même enzyme coagulante : 
TABLEAU IV bis

Tableau récapitulatif des \% d'explication et seuils de signification des écarts constatés entre préparations coagulantes, pour différentes variables rhéologiques

Summary of the explanation \% and significance thresholds of the differences seen between the coagulating preparation for different rheological variables

\begin{tabular}{|c|c|c|c|c|c|}
\hline Facteurs & $\mathrm{k} 10 / \mathrm{r}$ & $\mathrm{k} 100 / \mathrm{r}$ & $\mathrm{a} 0,5 \mathrm{r}$ & ar & $a 2 r$ \\
\hline Nature de l'enzyme & $68 \% *$ & $98,04 \% * * *$ & & $97,42 \% * * *$ & $92,71 \% * *$ \\
\hline $\mathrm{Mm}_{1} / \mathrm{EP}_{1}$ & $\mathrm{Mm}_{1} \mathrm{EP} \mathrm{P}_{1}$ & $\mathrm{Mm}_{1} \quad \mathrm{EP}_{1}$ & & $\underline{M m_{1}} \quad \underline{E P_{1}}$ & $\mathrm{Mm}_{1} \quad \mathrm{EP}{ }_{1}$ \\
\hline Endothia parasitica & $1,6 \% \quad \mathrm{NS}$ & $62,90 \% *$ & $72,35 \% *$ & $60,26 \% *$ & \\
\hline $\mathrm{ep}_{6} / \mathrm{EPC}_{1}$ & $\begin{array}{lll}\mathrm{ep}_{6} & \mathrm{EPC}_{1} \\
\end{array}$ & $\underline{\mathrm{ep}_{6}} \quad \underline{\mathrm{EPC}_{1}}$ & $\underline{\mathrm{ep}_{6}} \quad \underline{\mathrm{EPC}_{1}}$ & $\underline{\mathrm{ep}_{6}} \quad \underline{\mathrm{EPC}_{1}}$ & \\
\hline Nature du "support" & $1,93 \%$ NS & $39,91 \%$ NS & & $96,35 \% \quad * * *$ & $77,53 \% \quad *$ \\
\hline $\mathrm{Mm}_{1} / \mathrm{Mm}_{5}$ & $\mathrm{Mm}_{1} \quad \mathrm{Mm}_{5}$ & $\mathrm{Mm}_{1} \quad \mathrm{Mm}_{5}$ & & $\underline{\mathrm{Mm}} \mathrm{Mm}_{5}$ & $\mathrm{Mm}_{1} \quad \mathrm{Mm}_{5}$ \\
\hline Extraits de & $59,89 \% \quad *$ & $48,46 \% \quad N S$ & $59,98 \% *$ & $57,34 \% \quad N S$ & \\
\hline Présure concentrés & $\begin{array}{lll}E P C_{1} & \mathrm{EPC}_{2} & \mathrm{EPC}_{3} \\
\end{array}$ & $\mathrm{EPC}_{1} \mathrm{EPC}_{2} \quad \mathrm{EPC}_{3}$ & $\mathrm{EPC}_{1} \quad \mathrm{EPC}_{2} \quad \mathrm{EPC}_{3}$ & $\begin{array}{lll}E P C_{1} & E^{2} C_{2} & E^{2} C_{3} \\
\end{array}$ & \\
\hline
\end{tabular}

NS : Non significatif

* : Significatif au seuil de $\alpha=0,05$

** : Significatif au seuil de $\alpha=0,01$

*** : Hautement significatif au seuil de $\alpha=0,001$ 


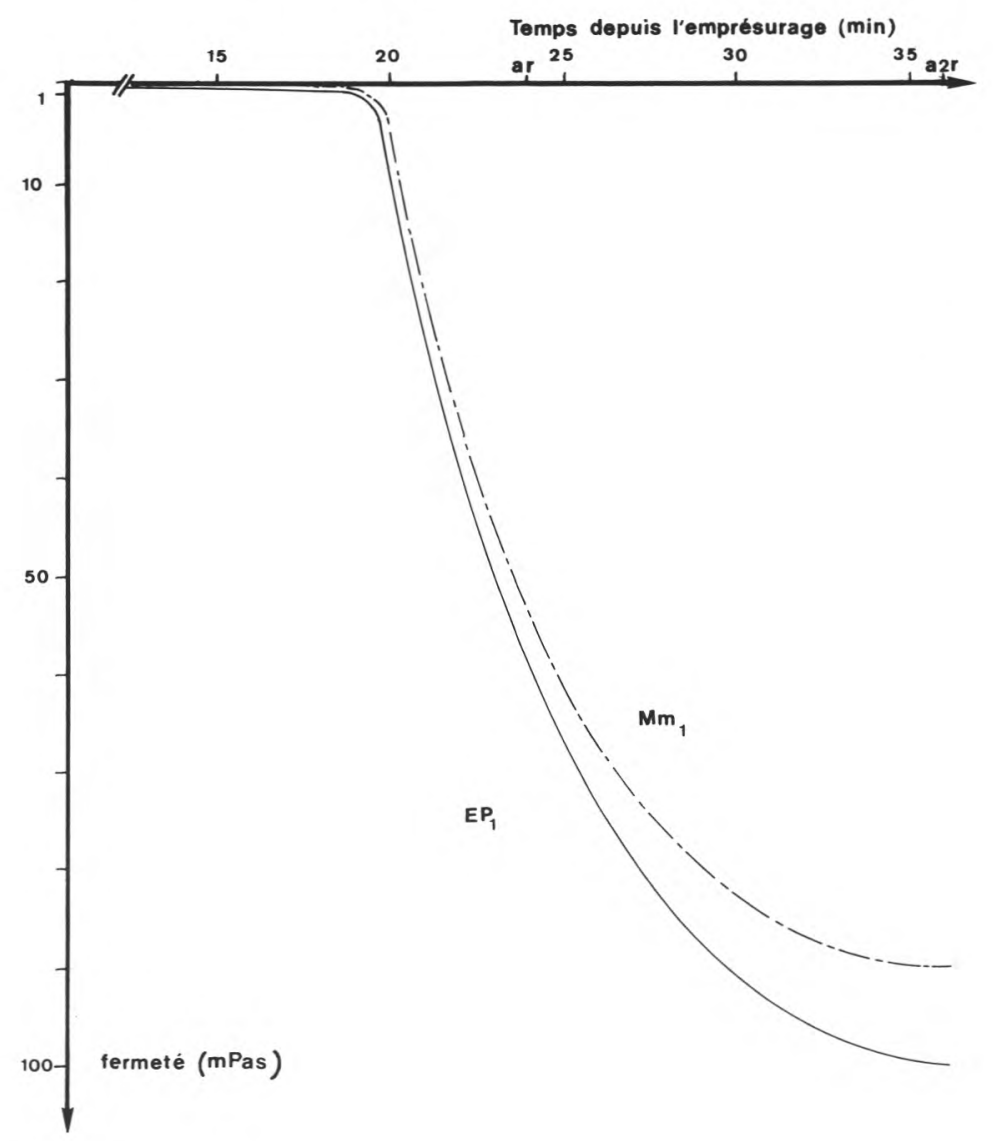

Fig. 2

Exemple de tracé sur Gélograph. Protocole type pâte molle - lait reconstitué $(N=3)$. Example of Gelograph curve. Soft cheese production method-reconstituted milk $(N=3)$. $E P_{1}$ : extrait de présure; rennet extract.

$\mathrm{Mm}_{1}$ : préparation à base de Mucor miehei ; preparation of Mucor miehei.

- pour Mucor miehei (tabl. 5), les coagulum obtenus à l'aide de la préparation $\mathrm{Mm}_{1}$ étaient significativement plus fermes $(\alpha=0,001)$ que $\mathrm{Mm}_{5}$ après un durcissement équivalent à une fois et deux fois le temps de floculation.

L'analyse statistique des variances montrait que la nature du support pour ces enzymes expliquait $96 \%$ et $77,5 \%$ des variations de la fermeté à une fois et deux fois le temps de floculation. 


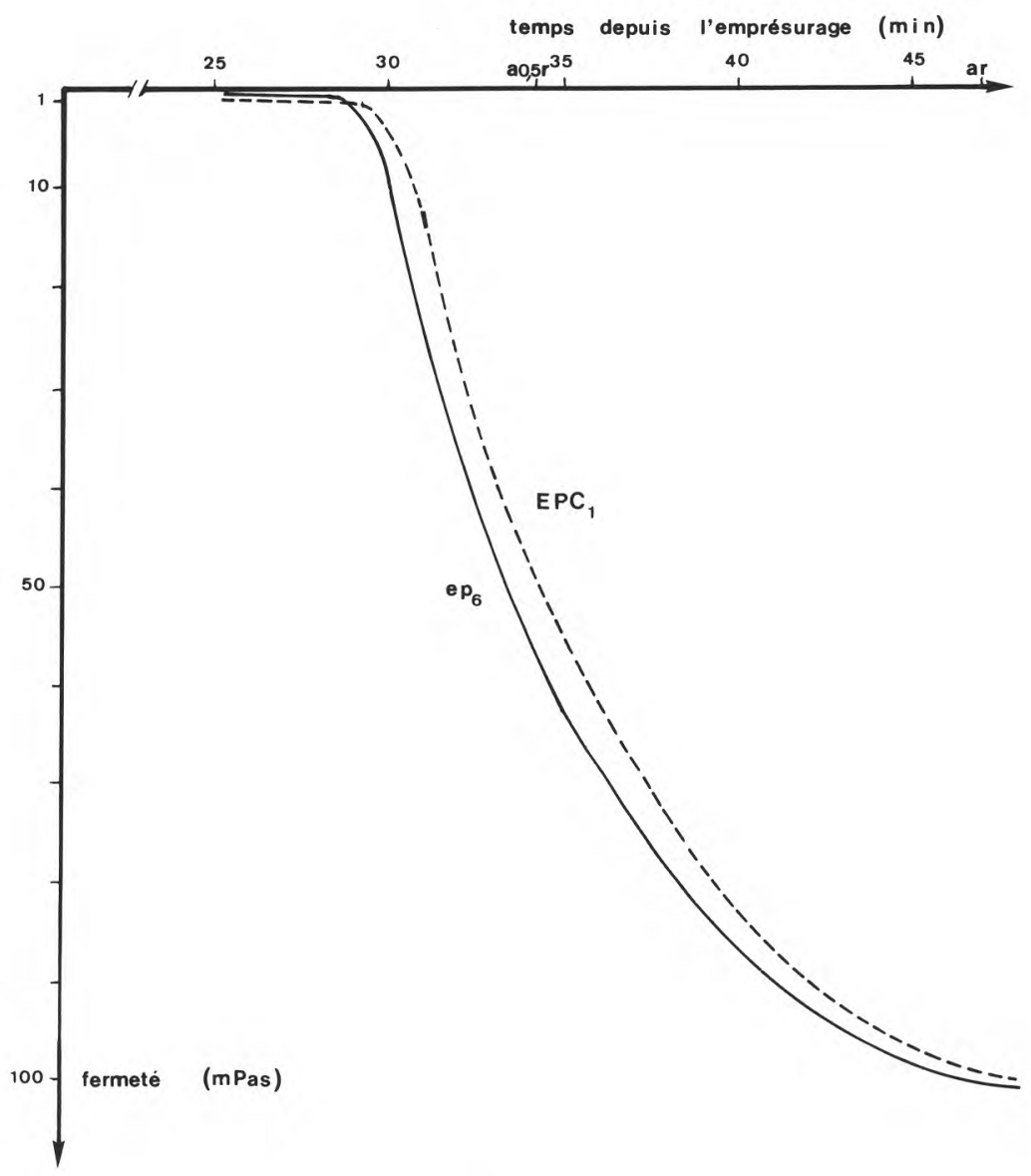

Fig. 3

Exemple de tracé sur Gélograph. Protocole type pâte pressée cuite - lait reconstitué $(N=3)$.

Example of Gelograph curve. Hard cheese production method - reconstituted milk $(N=3)$.

$E P C_{I}$ : extrait de présure concentré; concentrated rennet extract.

$\mathrm{ep}_{6} \quad$ : Endothia parasitica; Endothia parasitica.

- Pour les extraits de présure (tabl. 6), aucune différence significative n'était enregistrée en ce qui concerne la fermeté du coagulum. Cependant, l'extrait de présure $\mathrm{EP}_{1}$ a toujours donné des gels légèrement plus fermes quelque soit le temps de durcissement.

- Pour les extraits de présure concentrés (tabl. 7), $\mathrm{EPC}_{1}$ engendrait une évolution significativement plus lente $(\alpha=0,05)$ par rapport à $\mathrm{EPC}_{2}$ et $\mathrm{EPC}_{3}$. 
Des différences significatives $(\alpha=0,05)$ de fermeté de coagulum $(\mathrm{k} 10 / \mathrm{r})$ après un durcissement équivalent à 0,5 fois le temps de floculation étaient observées.

La préparation $\mathrm{EPC}_{1}$ donnait toujours les gels les plus fermes et $\mathrm{EPC}_{3}$ les moins fermes.

TABLEAU V

Etude du rôle du "support "sur Gélograph - résultats comparatifs avec Mucor miehei Study of the role of "diluting solution" with Gélograph - comparative results with Mucor miehei

\begin{tabular}{|l|c|c|}
\hline \multicolumn{1}{|c|}{ Echantillons } & $\mathrm{Mm}_{1}$ & $\mathrm{Mm}_{5}$ \\
\hline Nombre de répétitions & $\mathrm{N}=3$ & $\mathrm{~N}=3$ \\
\hline Dose d'emprésurage $\mathrm{ml} / 100 \mathrm{l}$ & 40 & 40 \\
\hline $\mathrm{r}:$ temps de prise (s) & 720 & 720 \\
\hline $\mathrm{k} 10 / \mathrm{r}$ & 1,732 & 1,868 \\
\hline $\mathrm{k} 100 / \mathrm{r}$ & 2,64 & 2,83 \\
\hline $\mathrm{ar}$ (mPas) & 33,8 & 22 \\
\hline $\mathrm{a} 2 \mathrm{r}$ (mPas) & 146,5 & 123 \\
\hline
\end{tabular}

TABLEAU VI

Etude du rôle du "support" sur Gélograph - résultats comparatifs avec des extraits de présure

Study of the role of "diluting solution » with Gelograph - comparative results with rennet extracts

\begin{tabular}{|l|c|c|c|c|}
\hline \multicolumn{1}{|c|}{ Echantillons } & $\mathrm{EP}_{1}$ & $\mathrm{EP}_{2}$ & $\mathrm{EP}_{3}$ & $\mathrm{EP}_{4}$ \\
\hline Nombre de répétitions & $\mathrm{N}=3$ & $\mathrm{~N}=3$ & $\mathrm{~N}=3$ & $\mathrm{~N}=3$ \\
\hline Dose d'emprésurage $\mathrm{ml} / 1001$ & 44,14 & 41,37 & 40 & 42,76 \\
\hline $\mathrm{r}:$ temps de prise (s) & 790 & 780 & 810 & 820 \\
\hline $\mathrm{k} 10 / \mathrm{r}$ & 1,189 & 1,202 & 1,21 & 1,23 \\
\hline $\mathrm{k} 100 / \mathrm{r}$ & 1,718 & 1,723 & 1,751 & 1,761 \\
\hline $\mathrm{ar}$ (mPas) & 163 & 150 & 148 & 148 \\
\hline $\mathrm{a} 2 \mathrm{r}$ (mPas) & 446 & 445 & 420 & 436 \\
\hline
\end{tabular}




\section{TABLEAU VII}

Etude $d u$ rôle $d u$ "support » sur Gélograph - résultats comparatifs avec des extraits de présure concentrés

Study of the role of " diluting solution " with Gelograph - comparative results with concentrated rennet extracts

\begin{tabular}{|l|c|c|c|}
\hline \multicolumn{1}{|c|}{ Echantillons } & $\mathrm{EPC}_{1}$ & $\mathrm{EPC}_{2}$ & $\mathrm{EPC}_{3}$ \\
\hline Nombre de répétitions & $\mathrm{N}=3$ & $\mathrm{~N}=3$ & $\mathrm{~N}=3$ \\
\hline Dose d'emprésurage $\mathrm{ml} / 1001$ & 20,6 & 22 & 20,66 \\
\hline $\mathrm{r}:$ temps de prise (s) & 1530 & 1530 & 1560 \\
\hline $\mathrm{k} 10 / \mathrm{r}$ & 1,243 & 1,255 & 1,292 \\
\hline $\mathrm{k} 100 / \mathrm{r}$ & 2,098 & 2,157 & 2,154 \\
\hline $\mathrm{a} 0,5 \mathrm{r}$ (mPas) & 36 & 34 & 30 \\
\hline ar (mPas) & 85 & 82 & 82 \\
\hline
\end{tabular}

\section{Fabrications fromagères expérimentales}

1. Fabrications de pâtes molles - séries $A, B$ et $C$

Le tableau 8 donne les principaux résultats technologiques de ces fabrications. Les différences qui apparaissent peuvent être imputées :

- A la nature des «supports »: comparaison de $\mathrm{Mm}_{1} / \mathrm{Mm}_{5}$

- pour la série A, en ce qui concerne la coagulation, les gels obtenus avec $\mathrm{Mm}_{5}$ étaient jugés tactilement plus souples qu'avec $\mathrm{Mm}_{1}$. La préparation $\mathrm{Mm}_{1}$ conduisait à des extraits secs totaux (EST) au démoulage, plus élevés : $+1,9 \%$ (différence significative au seuil de $\alpha=0,05$ ). Ceci pour des $\mathrm{pH}$ au démoulage semblables ;

- pour la série $B$, une légère stimulation de l'acidification des caillés obtenus à l'aide du coagulant $\mathrm{Mm}_{1}$ était observée ;

- pour l'ensemble des trois séries, l'emploi de $\mathrm{Mm}_{1}$ donnait les meilleurs rendements, en moyenne $+2 \%$ par rapport à $\mathrm{Mm}_{5}$ (différence significative au seuil de $\alpha=0,05)$. L'analyse des coefficients de récupération montrait que le gain d'EST était essentiellement dû (séries $\mathrm{B}$ et $\mathrm{C}$ ) à une meilleure récupération de la matière grasse (MG).

- A l'effet dose du «support»: comparaison de $\mathrm{Mm}_{1} / \mathrm{Mm}_{1}+\mathrm{S}_{1}$

Pour les séries $\mathrm{B}$ et $\mathrm{C}$, l'emploi de $\mathrm{Mm}_{1}+\mathrm{S}_{1}$ donnait :

- des temps de floculation légèrement plus courts, tandis que le temps de descente en moule était considérablement augmenté ;

- une acidification, significativement supérieure $(\alpha=0,05)$ dans les 3 premières heures, des caillés des fabrications réalisées au mois de novembre (série B) ; 


\section{TABleau VIII}

Principaux résultats obtenus sur les fabrications de pâtes molles (séries $A, B$ et $C$ ) Results obtained in soft cheese production (series $A, B$ and $C$ )

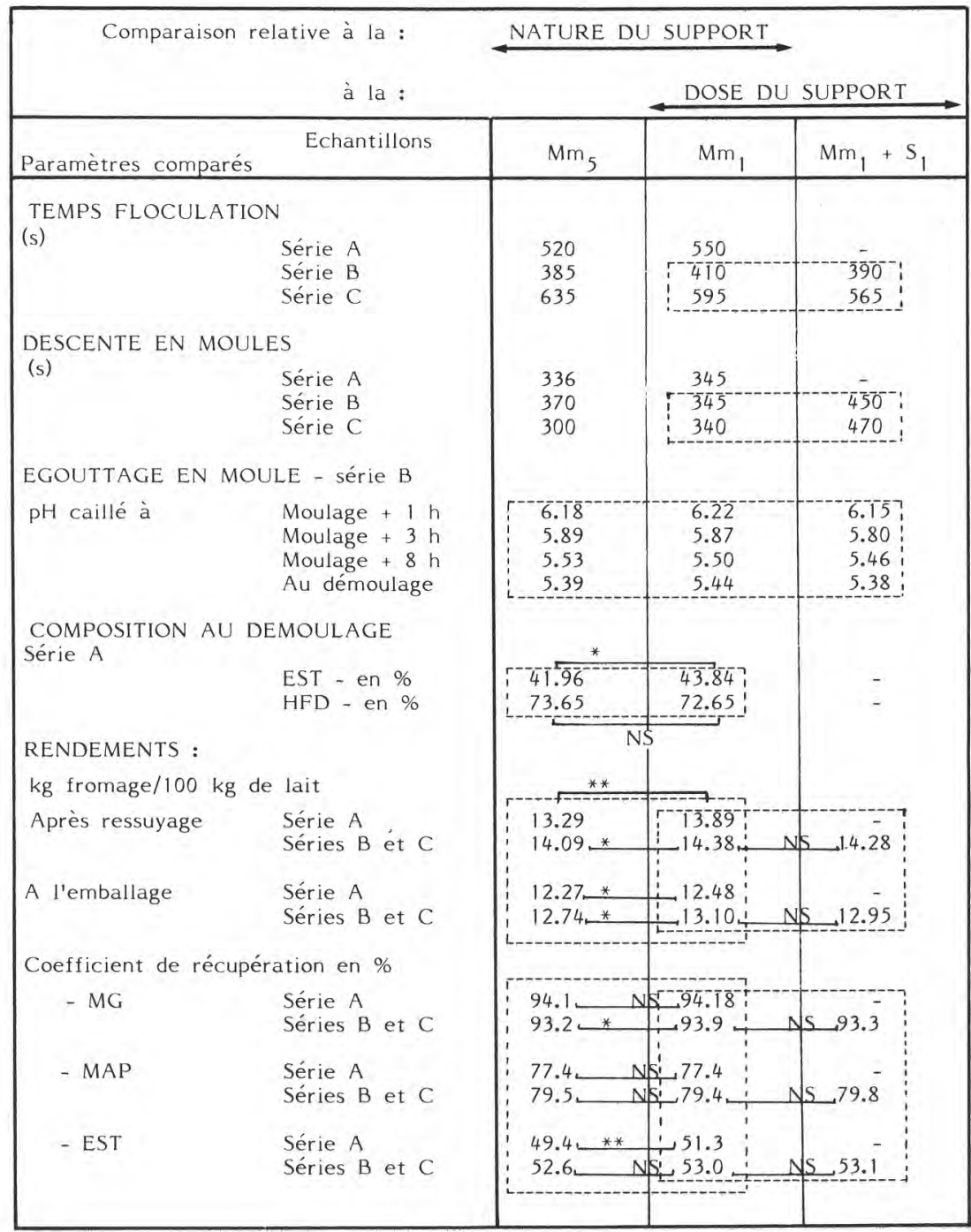

Séries $A, B$ et $C$.

HFD : Humidité dans le fromage dégraissé EST : Extrait sec total

MG : Matière grasse

MAP : Matière azotée protéique
NS : Non significatif

* : Significatif au seuil de $\alpha=0,05$

** : Significatif au seuil de $\alpha=0,01$ 
- des rendements très légèrement inférieurs ( $-1 \%$ en moyenne) à ceux de $\mathrm{Mm}_{1}$ (différence non significative);

- de moins bons résultats que $\mathrm{Mm}_{1}$ au point de vue organoleptique.

\section{Fabrication de pâtes molles solubilisées - série $D$}

Dans cette série, il était comparé différentes présures: $\mathrm{EP}_{1}, \mathrm{EPC}_{1}, \mathrm{EP}_{2}$, $\mathrm{EP}_{3}, \mathrm{EP}_{4}$. Le tableau 9 donne une synthèse des principaux résultats technologiques. Les différences les plus marquantes peuvent être imputées :

- A la nature du "support"

- Lors de l'égouttage en moule, le contrôle des poids de caillé montre que l'ensemble des essais avait la même cinétique d'égouttage, mais que les essais $E P_{1}$ et $E P C_{1}$ avaient toujours des poids supérieurs aux essais $E_{2}, E_{3}$ et $\mathrm{EP}_{4}$, tandis qu' $E P_{3}$ avait les poids les plus faibles après 30 min et $8 \mathrm{~h}$.

- Au démoulage, les essais $\mathrm{EP}_{1}$ et $\mathrm{EPC}_{1}$ étaient significativement mieux égouttés. A l'emballage, les écarts d'EST entre $\mathrm{EP}_{1}, \mathrm{EPC}_{1}, \mathrm{EP}_{2}$ et $\mathrm{EP}_{3}$ sont significatifs $(\alpha=0,05)$.

- L'ensemble des essais avait des valeurs de $\mathrm{pH}$ au démoulage comparables. Mais à $\mathbf{J}+5$, la présure $\mathrm{EP}_{1}$ entraînait la post-acidification la moins importante (signification non vérifiée); à $\mathbf{J}+10$, les présures $\mathrm{EP}_{2}$ et $\mathrm{EP}_{3}$ conduisaient à observer un $\mathrm{pH}$ proche de $\mathbf{J}+2$.

- Les rendements, déterminés au démoulage ou à l'emballage des fabrications emprésurées à l'aide de $\mathrm{EP}_{1}$ et $\mathrm{EPC}_{1}$ étaient significativement supérieurs $(\alpha=0,05)$ à ceux obtenus avec $\mathrm{EP}_{2}$ ou $\mathrm{EP}_{3}$. L'écart entre ces deux groupes de présures était de $3,4 \%$ au démoulage, et de $1,1 \%$ à l'emballage. Cette amélioration de rendement trouve son origine dans une meilleure récupération de la matière grasse et de l'extrait sec dégraissé du lait dans le fromage.

- Au niveau organoleptique, aucune différence significative n'était notée jusqu'à $\mathrm{J}+40$. Mais après un vieillissement prolongé jusqu'à $\mathrm{J}+60$ à $7{ }^{\circ} \mathrm{C}$, la «fleur » se maintenait mieux avec les présures $\mathrm{EP}_{1}, \mathrm{EPC}_{1}$ et $\mathrm{EP}_{3}$, tandis que la flaveur des essais $\mathrm{EP}_{3}$ se conservait le mieux.

- A l'effet dose mis en évidence par la comparaison des fabrications effectuées à partir de $\mathrm{EP}_{1}$ et $\mathrm{EPC}_{1}$. L'emprésurage effectué à l'aide d'une préparation apportant une dose supérieure de «support » conduisait à observer des temps de floculation plus courts. La descente en moule était beaucoup plus lente avec $\mathrm{EP}_{1}$ et $\mathrm{EPC}_{1}$ qu'avec les autres présures.

\section{Fabrication d'emmental - série $E$}

Ces essais comparaient les effets de trois préparations coagulantes: deux extraits de présure concentrés $\mathrm{EPC}_{1}$ et $\mathrm{EPC}_{2}$ et Endothia parasitica $\mathrm{ep}_{6}$.

- Coagulation, comportement rhéologique des laits emprésurés et égouttage

- Pour des temps de floculation semblables ( $25 \mathrm{~min}$ en moyenne), les temps de durcissement observés et mesurés étaient très différents suivant les préparations coagulantes utilisées comme le montrent les résultats de la figure 4. 


\section{TABLEAU IX}

Principaux résultats obtenus sur des fabrications de pâtes molles (série D) Results obtained in soft cheese production (serie D)

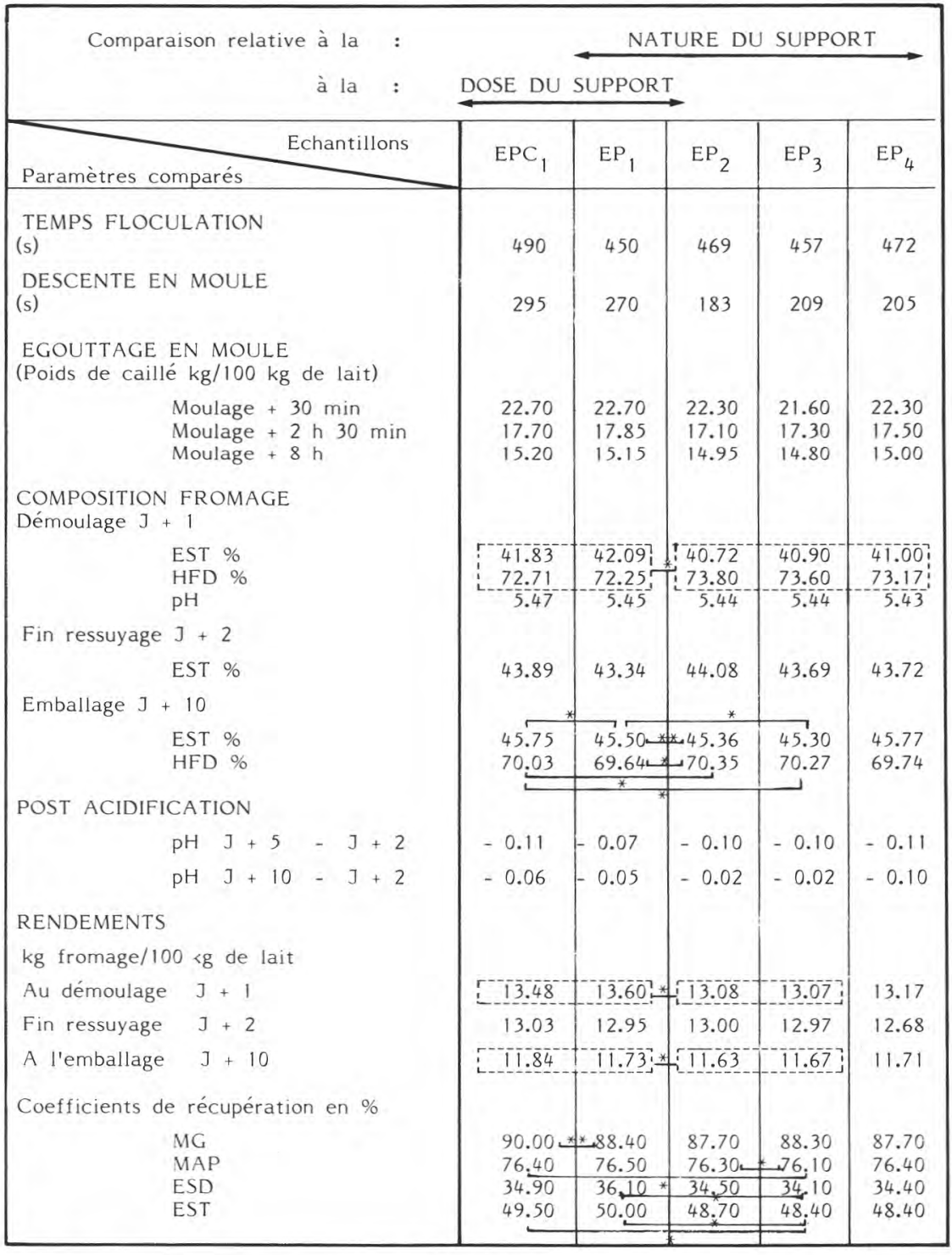

Série $D$.

* = Significatif au seuil de $\alpha=0,05$

** $=$ Significatif au seuil de $\alpha=0,01$ 


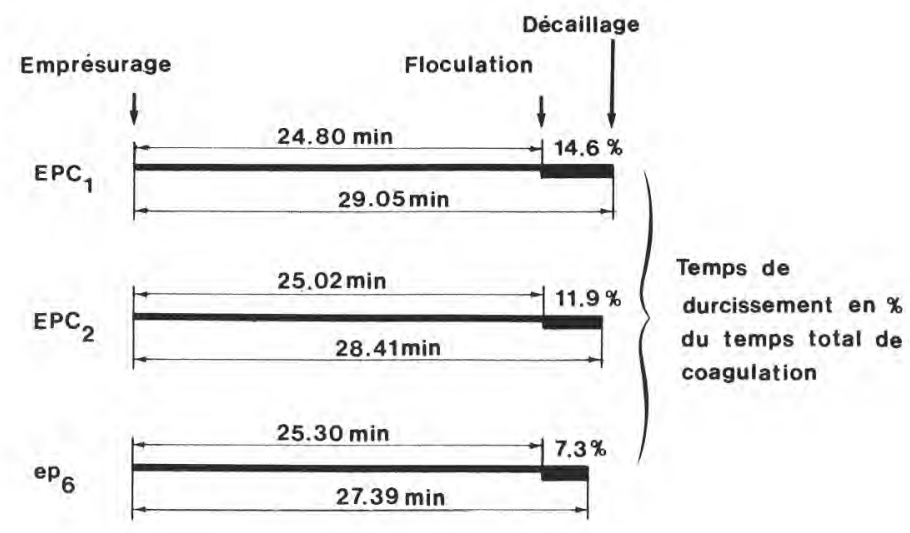

Fig. 4

Temps de coagulation et de décaillage observés en technologie emmental.

Coagulation and curd cutting times observed in emmental technology.

$E P C_{1}$ : extrait de présure concentré.

concentrated rennet extract.

$E P C_{2}$ : extrait de présure concentré. concentrated rennet extract.

ep $p_{6} \quad$ : Endothia parasitica.

Endothia parasitica.

- Les mesures rhéologiques effectuées en parallèle au travail en cuve de fabrication (tabl. 10) indiquaient que le décaillage était commencé à une valeur moyenne de $65 \mathrm{mPas} \pm 10 \%$ (une variation de fermeté de $10 \%$ correspond dans cette plage à $20 \mathrm{~s}$ ), et montraient la bonne adaptation du praticien fromager aux différents coagulants.

- Comparativement à $\mathrm{EPC}_{1}$ et $\mathrm{EPC}_{2}$, ep $\mathrm{ep}_{6}$ donnait un gel qui durcissait très vite ; le temps de durcissement était approximativement deux fois plus court pour obtenir une fermeté de gel comparable au décaillage.

- Après décailllage, les évolutions de fermeté de $\mathrm{EPC}_{1}$ et $\mathrm{ep}_{6}$ étaient comparables tout en ayant une fermeté supérieure à $\mathrm{EPC}_{2}$.

- Lors de l'égouttage en cuve, par appréciation tactile, il était noté que la contraction des grains était plus tardive avec $\mathrm{ep}_{6}$. Elle débutait seulement vers $48{ }^{\circ} \mathrm{C}$ lors du chauffage.

Le comportement particulier de $\mathrm{ep}_{6}$ par rapport à $\mathrm{EPC}_{1}$ et $\mathrm{EPC}_{2}$, c'est-àdire une organisation rapide du gel avant décaillage suivie d'une organisation plus lente lors de l'égouttage en cuve est en accord avec l'enregistrement rhéologique (fig. 3).

- Au démoulage, pour des $\mathrm{pH}$ de caillé et humidité dans le fromage dégraissé (HFD) identiques, les fromages réalisés avec EPC $C_{1}$ avaient des EST significativement plus élevés $(\alpha=0,05)$ de 0,3 point comparés à $\mathrm{EPC}_{2}$ et $\mathrm{ep}_{6}$ (tabl. 10). 


\section{TABLEAU $\mathrm{X}$}

Principaux résultats obtenus sur des fabrications d'emmental (série E) Results obtained in emmental production (serie E)

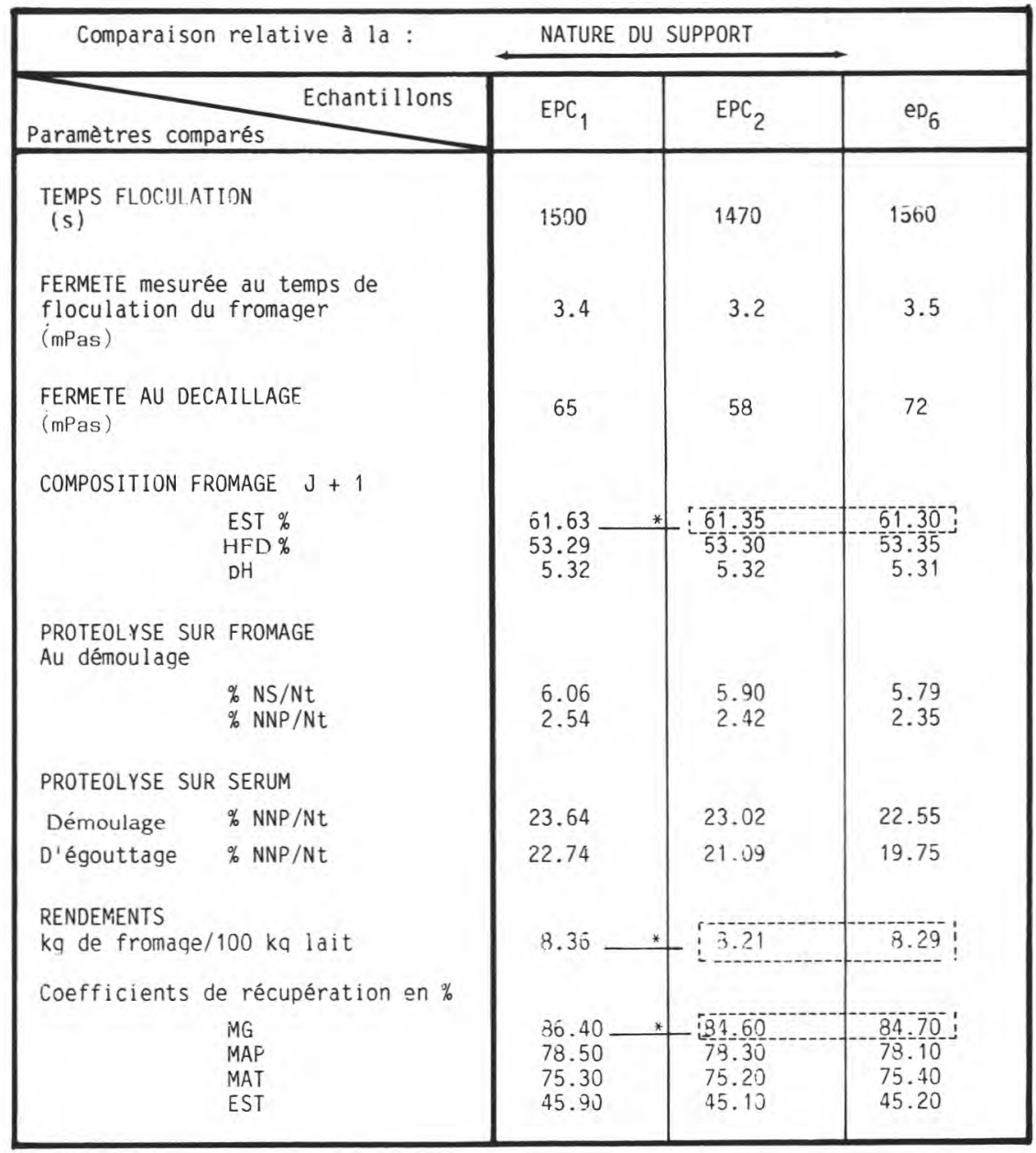

Série E.

* : Significatif au seuil de $\alpha=0,05$

- Le niveau de protéolyse des fromages au démoulage (\% de NS/Nt et $\%$ de $\mathrm{NNP} / \mathrm{Nt}$ ), décroissait de $\mathrm{EPC}_{1}$ à $\mathrm{EPC}_{2}$ et ep $\mathrm{p}_{6}$. Ces résultats sont confirmés par l'analyse des sérums prélevés soit au moulage, soit à l'égouttage.

- Les fromages obtenus avec $\mathrm{ep}_{6}$ avaient la durée de passage en cave chaude la plus courte $(30 \mathrm{j})$ (tabl. 11).

- La formation la plus rapide de l'ouverture était obtenue ave $\mathrm{ep}_{6}$ et la plus lente avec $\mathrm{EPC}_{1}$. La différence entre ces deux coagulants était significative au seuil de $\alpha=0,05$. 
- Les fromages fabriqués avec $\mathrm{EPC}_{1}$ tendaient à perdre plus de poids en cours d'affinage sans que la différence ait été significative. Cette perte semblait acquise dès l'entrée en cave chaude (tabl. 11).

- La protéolyse estimée, à la coupe, par l'indice d'affinage (exprimé en valeur absolue) (tabl. 11) montrait que $\mathrm{ep}_{6}$ conduisait à l'obtention des fro-

TABLEAU XI

Principaux résultats de l'affinage des emmentals (série E)

Results of emmental ripening (serie E)

\begin{tabular}{|c|c|c|c|}
\hline Comparaison relative à la: & \multicolumn{2}{|c|}{ NATURE DU SUPPORT } & \multirow[b]{2}{*}{$\mathrm{eD}_{6}$} \\
\hline Paramètres comparés Echantillons & $\mathrm{EPC}_{1}$ & $\mathrm{EPC}_{2}$ & \\
\hline \multirow{2}{*}{$\begin{array}{l}\text { DUREE PASSAGE CAVE CHAUDE } \\
\text { (jours) } \\
\text { VITESSE DE FORMATION DE } \\
\text { L'OUVERTURE. (*) }\end{array}$} & 35 & 33 & 30 \\
\hline & 70.5 & 78.8 & 85.7 \\
\hline \multirow{4}{*}{$\begin{array}{l}\text { PERTE DE POIDS CUMULEE en \% } \\
\text { Entrée cave chaude } \\
\text { Sortie cave chaude } \\
\text { coupe }\end{array}$} & & & \\
\hline & 4.45 & 3.84 & 4.11 \\
\hline & 8.26 & 7.56 & 7.69 \\
\hline & 9.02 & 3.45 & 8.64 \\
\hline \multirow{4}{*}{$\begin{array}{l}\text { INDICE AFFINAGE } \quad(* *) \\
\text { Entrée cave chaude } \\
\text { Sortie cave chaude } \\
\text { Coupe }\end{array}$} & & & \\
\hline & 0.124 & 0.123 & 0.122 \\
\hline & 0.242 & 0.232 & 0.251 \\
\hline & 0.241 & 0.242 & 0.263 \\
\hline \multirow{2}{*}{$\begin{array}{l}\text { FORCE D'EXTRUSION } \\
\text { A la découpe en } \mathrm{kg} \\
\text { ANALYSE SENSORIELLE } \\
\text { Sur fromages à la coupe }\end{array}$} & 4.60 & 4.82 & 4.35 \\
\hline & & & \\
\hline / 5 points & 3.7 & 4.0 & 3.9 \\
\hline / 5 points & 4.1 & 4.4 & 4.3 \\
\hline / 10 points & 5.9 & 5.9 & 5.6 \\
\hline I 5 points & 3.8 & 3.8 & 3.5 \\
\hline / 5 points & 3.4 & 3.7 & 3.4 \\
\hline Sur cubes de fromage & & & \\
\hline / 5 points & 3.7 & 3.8 & 3.2 \\
\hline$/ 10$ points & 5.1 & 5.5 & 4.9 \\
\hline
\end{tabular}

Série E.

(*) Vitesse de formation de l'ouverture $=\frac{\text { hauteur fromage }}{\text { largeur fromage } \mathrm{x} \text { temps passage en cave }}$.

$(* *) \quad$ Indice d'affinage $=$ valeur absolue du point de congélation mesuré

chaude 
mages significativement $(\alpha=0,05)$ les plus protéolysés après un mois de stockage en cave froide.

- De même, $\mathrm{ep}_{6}$ donnait des fromages ayant la pâte la moins ferme (par l'emploi de la technique de détermination de la force d'extrusion) (tabl. 11).

- Les fromages réalisés avec $\mathrm{EPC}_{1}$ et $\mathrm{EPC}_{2}$ avaient tendance à avoir une ouverture moins chargée qu'avec $\mathrm{ep}_{6}$.

- Les textures des fromages obtenus avec $\mathrm{EPC}_{1}$ et $\mathrm{EPC}_{2}$ étaient jugées agréables, voire un peu plus fermes que celles des fromages fabriqués avec $\mathrm{ep}_{6}$. $\mathrm{ep}_{6}$ donnait une pâte à tendance collante et pâteuse. Ces résultats sont en accord avec la mesure de la force d'extrusion.

- Au niveau de la flaveur, $\mathrm{ep}_{6}$ donnait les moins bons fromages; des saveurs acides-amères étaient signalées. Dans les deux modes de jugement utilisés, $\mathrm{EPC}_{2}$ donnait les meilleurs résultats.

\section{- Rendements}

$\mathrm{EPC}_{1}$ donnait significativement $(\alpha=0,05)$ les meilleurs rendements ; $\mathrm{EPC}_{2}$, les moins bons (tabl. 10). Les écarts étaient de $0,8 \%$ entre $\mathrm{EPC}_{1}$ et ep $\mathrm{ep}_{6}$ et de $1,8 \%$ entre $\mathrm{EPC}_{1}$ et $\mathrm{EPC}_{2}$. Ces écarts s'expliquaient essentiellement par une meilleure récupération de la $\mathrm{MG}$ du lait dans les essais avec $\mathrm{EPC}_{1}$.

\section{Discussion - Conclusions}

Comparés à la présure de veau, les différents types d'enzymes coagulantes testées : Mucor miehei, Endothia parasitica possèdent des aptitudes fromagères spécifiques. Mucor miehei donne des gels moins fermes, et Endothia parasitica provoque une organisation du caillé nettement plus rapide (tabl. 10 ; fig. 2 et 3). Ces résultats sont en accord avec les données de RAMET et al. (1969) et de GreEN (1977).

L'étude de la composition biochimique des «supports " des préparations coagulantes étudiées montre des différences importantes pour le chlorure $(\mathrm{NaCl})$, le phosphore $\left(\mathrm{P}_{2} \mathrm{O}_{5}\right)$ et l'azote non ammoniacal exprimé en \% de l'azote total.

Ces trois composants caractérisent bien le «support » découlant du procédé de fabrication de chaque fournisseur : la figure 5 montre qu'il existe peu de recoupements; les spécificités mises en évidence peuvent d'ailleurs être reliées aux processus de fabrication des différents présuriers: qualité de la matière première (teneur en $\mathrm{N}_{\mathrm{NH} 3}$ ), procédés d'extraction, méthode de purification, etc.

Les différences quantitatives observées pour ces composants biochimiques entraînent, en fabrication fromagère, pour une même addition de chymosine (soit $13 \mathrm{mg} / 100 \mathrm{l}$ de lait) ou de Mucor miehei ou d'Endothia parasitica, des apports de $\mathrm{NaCl}, \mathrm{P}_{2} \mathrm{O}_{5}$ et azote non ammoniacal différents, selon le «support » (tabl. 12). 
TABLEAU XII

Quantités de "support» apportées pour 100 l de lait (chiffres calculés sur une base d'emprésurage de $25 \mathrm{ml}$ d'extrait de présure pour 100 l de lait)

Amount of subsidiary elements added by the coagulant preparations for the coagulation of 100 liters of milk (datas calculated on the basis of rennetisation of addition of $25 \mathrm{ml}$ rennet extract per 100 l milk)

\begin{tabular}{|c|c|c|c|c|c|c|c|c|c|c|c|}
\hline & \multicolumn{8}{|c|}{ PRESURES } & \multicolumn{3}{|c|}{$\begin{array}{l}\text { ENZYMES D ORIGINE } \\
\text { MICROBIENNE }\end{array}$} \\
\hline & \multirow{2}{*}{$\begin{array}{r}\text { Presure } \\
\text { simple } \\
P_{1} \\
\end{array}$} & \multicolumn{4}{|c|}{ Extraits de présure } & \multicolumn{3}{|c|}{$\begin{array}{c}\text { Extraits de présure } \\
\text { concentrés }\end{array}$} & \multicolumn{2}{|c|}{ Mucor miehei } & $\begin{array}{r}\text { Endothia } \\
\text { barasitica }\end{array}$ \\
\hline & & $\mathrm{EP}_{1}$ & $\mathrm{EP}_{2}$ & $\mathrm{EP}_{3}$ & $\mathrm{EP}_{4}$ & $E P C_{1}$ & $\mathrm{EPC}_{2}$ & $\mathrm{EPC}_{3}$ & $\mathrm{Mm}_{1}$ & $\mathrm{Mm}_{5}$ & $\mathrm{ep}_{6}$ \\
\hline $\begin{array}{l}\text { Quantité de chymosine } \\
\text { (mg/l) de la } \\
\text { préparation } \\
\text { commerciale }\end{array}$ & 130 & 520 & 520 & 520 & 520 & 680 & 680 & 680 & - & - & - \\
\hline Nacl $(g / 1001)$ & 14.2 & 3,33 & 5.15 & 4,15 & 4.8 & 2.59 & 3.72 & 3.15 & 3,45 & 3,95 & $2,5 \cdot 10^{-3}$ \\
\hline $\mathrm{P}_{2} \mathrm{O}_{5} \quad(\mathrm{~g} / 100 \quad 1)$ & 0,9 & 0,25 & 0.05 & 0.05 & 0.05 & 0.2 & 0.04 & 0.05 & 0.23 & 0.02 & $2.8 \cdot 10^{-3}$ \\
\hline$N t-N_{N H 3}(g / 1001)$ & 0.14 & 0,06 & 0.05 & 0.03 & 0.05 & 0.04 & 0.03 & 0.02 & 0.05 & $2.10^{-3}$ & $1,25 \cdot 10^{-3}$ \\
\hline
\end{tabular}




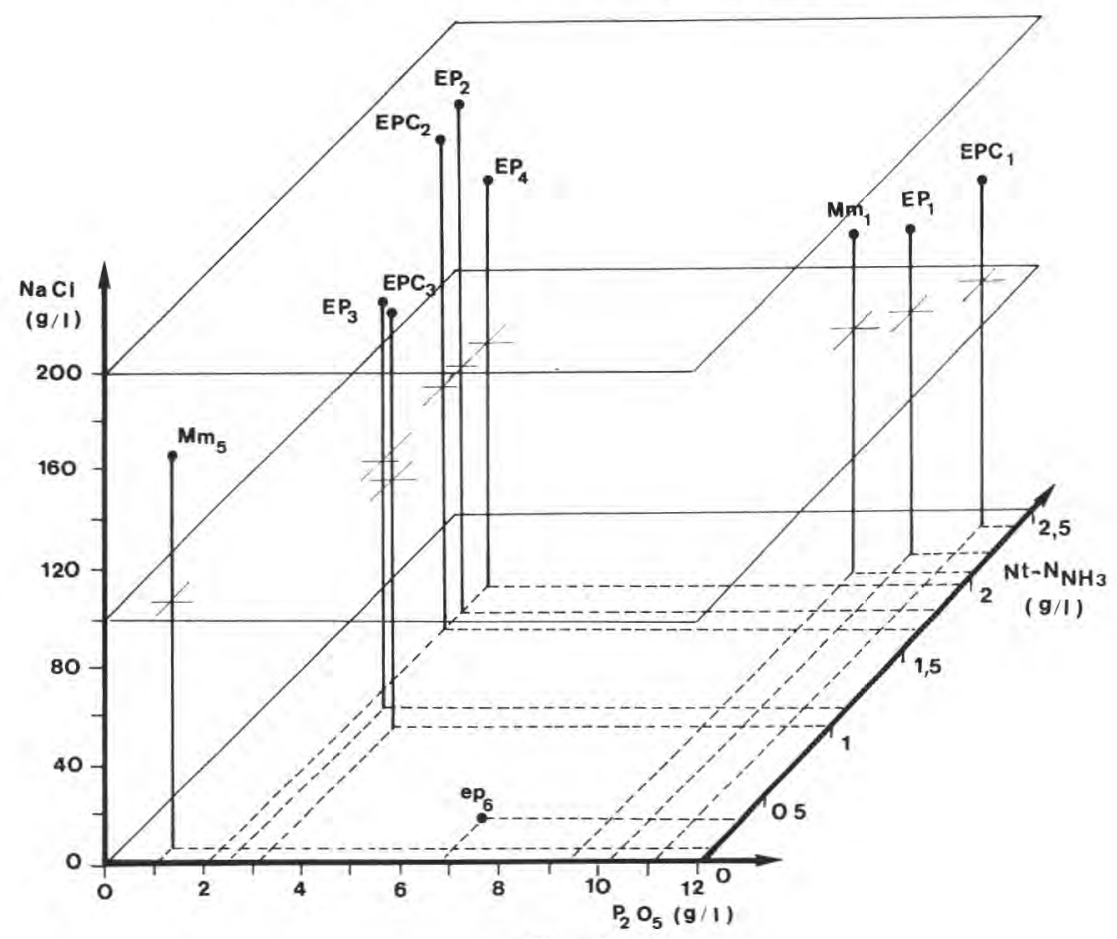

Fig. 5

Représentation graphique de la composition chimique des "supports " des préparations coagulantes.

Graphic representation of the chemical concentration of "diluting solutions " of coagulants.

Ces apports peuvent paraître faibles comparés à la composition du lait. Néanmoins, en fabrications expérimentales, des modifications significatives de comportement peuvent être mises en évidence. Les écarts constatés sont comparables et parfois même supérieurs aux différences notées entre enzymes.

La stimulation observée dans les essais emprésurés à l'aide des préparations du fournisseur $n^{\circ} 1$ confirment en fabrication expérimentale de fromages à pâte solubilisée (série $\mathrm{B}$ ) les résultats précédemment obtenus au laboratoire, où il avait été montré que cette stimulation était liée à la présence de peptides de poids moléculaire voisin de 1300 (fraction b de la fig. 1) (Mietton et al., 1982 ; QuiBLIER, 1982).

Le fait que cette stimulation ait été notée seulement sur les essais B est probablement à relier à la date de réalisation de ces fabrications (novembre), où les laits de Franche-Comté sont en effet réputés pour avoir à cette période de l'année, un moindre pouvoir acidifiant. Compte tenu de la faible teneur en plasmine des laits produits à cette époque (BEN SLIMANe, 1986), il est permis de penser que ce moindre pouvoir acidifiant serait dû à une plus faible teneur en petits peptides résultant de l'action de cette enzyme sur la caséine $\beta$. Le rôle activateur de ces petits peptides sur Streptococcus thermophilus est bien connu (Desmazeaud et Hermier, 1972). L'addition aux laits de fabrication de 
« supports » d'enzymes coagulantes riches en petits peptides de composition voisine permettrait de pallier cette déficience en azote peptidique des laits de novembre.

Quant à la différence d'intensité de stimulation constatée entre les résultats de Mietton et al. (1982) et ceux rapportés dans le présent travail, elle est probablement due au fait que le schéma de fabrication de fromage à pâte stabilisée comportait une étape de prématuration du lait à basse température (12-13 ${ }^{\circ} \mathrm{C}$ pendant $16-18$ heures). Cette prématuration devait être à même de compenser l'insuffisance initiale de facteurs de croissance et donc, masquer partiellement l'effet activateur des «supports » d'enzyme.

D'importants écarts apparaissent pour les temps de descente en moule en pâtes molles (séries B et C; tabl. 8 - série D ; tabl. 9) et pour les temps de durcissement en emmental (série E; tabl. 10). Ces écarts confirment les résultats obtenus en rhéologie (rôle du support ; tabl, 5, 6 et 7). Ils peuvent être reliés aux apports de minéraux par les «supports »:

a) L'apport de $\mathrm{NaCl}$ varie entre 2,5 et $5,15 \mathrm{~g}$ pour 1001 de lait en fonction de la nature du «support ». De telles variations peuvent provoquer des modifications en fabrication, compte tenu du double effet du $\mathrm{NaCl}$ :

- Sur le temps de prise, jusqu'à $0,1 \%$ (soit $100 \mathrm{~g}$ pour 1001 ), le salage du lait provoque une réduction du temps de floculation par la présure. Ces résultats sont effectivement notés lors des séries $\mathrm{A}, \mathrm{B}, \mathrm{D}$ et $\mathrm{E}$ (tabl. 8,9 et 10). Pour Mucor miehei (non thermolabile), il est constaté le même effet jusqu'à $0,5 \%$ (SCRIBAN, 1984).

- Sur l'organisation du caillé, l'addition de chlorure de sodium au lait solubilise du calcium micellaire. Le déplacement calcique vers la phase aqueuse réduit les possibilités d'organisation du caillé et peut également s'accompagner d'une solubilisation des caséines (Brule et LenOIR, 1984).

Ces deux conséquences sont vérifiées pour l'ensemble des fabrications expérimentales. Une augmentation de l'apport de $\mathrm{NaCl}$ par les coagulants s'accompagne :

- d'un raccourcissement des temps de prise et des temps de descente en moules (tabl. 8, 9 et 10 ; fig. 6) ;

- d'une diminution des EST et une augmentation des HFD au démoulage (tabl. 8,9 et 10 ; fig. 7 ) ;

- les calculs des rendements fromagers révèlent des écarts significatifs de l'ordre de $2 \%$ en pâtes molles comme en pâtes pressées cuites (série A, B et C ; tabl. 8 - série D ; tabl. 9 - série E; tabl. 10). Ces écarts sont essentiellement liés à une meilleure récupération de la $\mathrm{MG}$, du fait d'une meilleure organisation des gels et d'une plus grande latitude laissée au fromager pour apprécier tactilement le moment optimum du décaillage.

Les écarts de rendement (fig. 8 et 9) peuvent être, en partie, expliqués par le rôle du $\mathrm{NaCl}$. La préparation coagulante ep Endothia parasitica, pourtant pauvre en $\mathrm{NaCl}$, a occasionné des différences sensibles en $\mathrm{MG}$ dans le sérum (tabl. 10), car la rapidité d'organisation du coagulum conduisait à décailler plus rapidement. $\mathrm{La}$ présence de $\mathrm{NaCl}$ dans le «support » de $\mathrm{ep}_{6}$ accentuerait encore ce phénomène et limiterait la synérèse finale du gel lors de l'égouttage. 


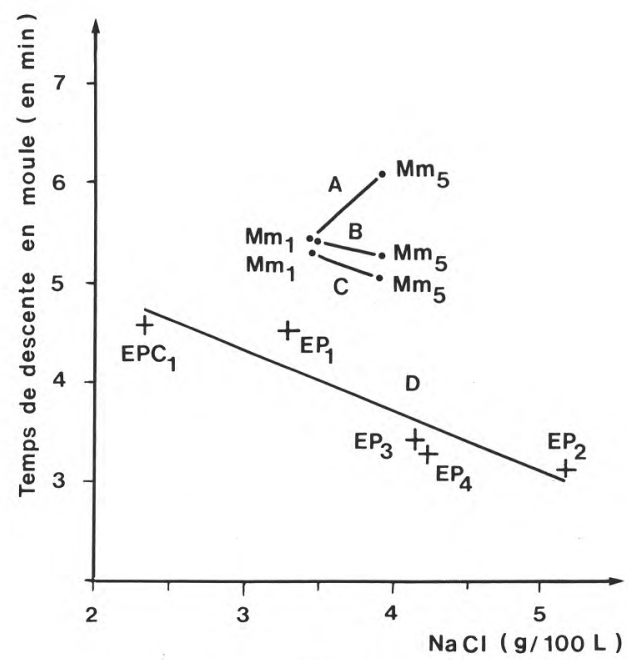

Fig. 6

Incidence de l'apport de $\mathrm{NaCl}$ par les préparations coagulantes sur le temps de descente en moule.

Effect of $\mathrm{NaCl}$ contents of the different coagulant preparations on drainage time.

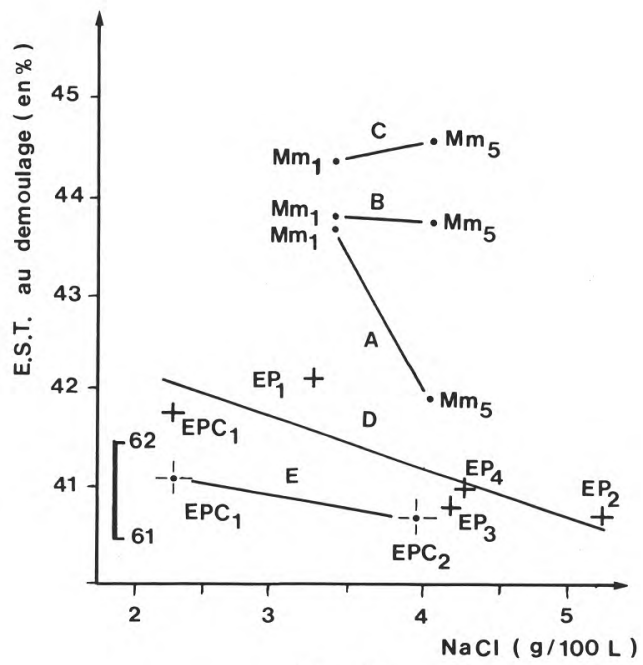

Fig. 7

Incidence de l'apport de $\mathrm{NaCl}$ par les préparations coagulantes sur l'extrait sec au démoulage.

Effect of $\mathrm{NaCl}$ contents of the different coagulant preparations on total solids of curds. 


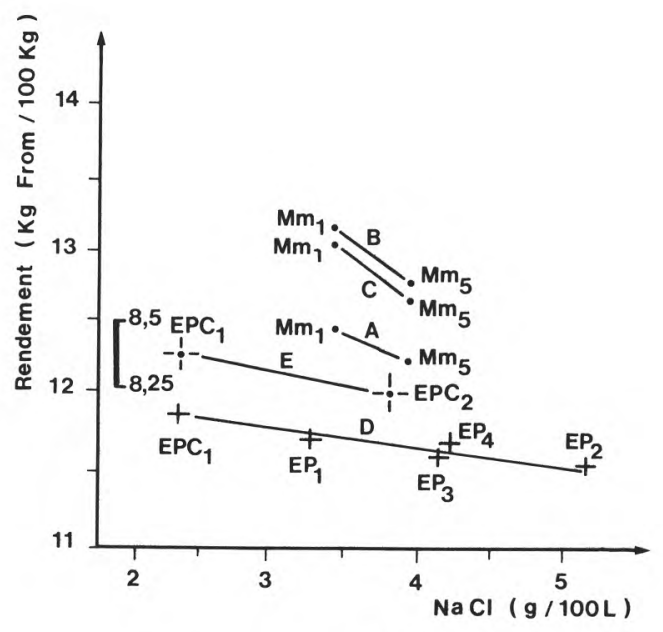

Fig. 8

Incidence de l'apport de $\mathrm{NaCl}$ par les préparations coagulantes sur les rendements. Effect of $\mathrm{NaCl}$ contents of the different coagulant preparations on cheese yield.

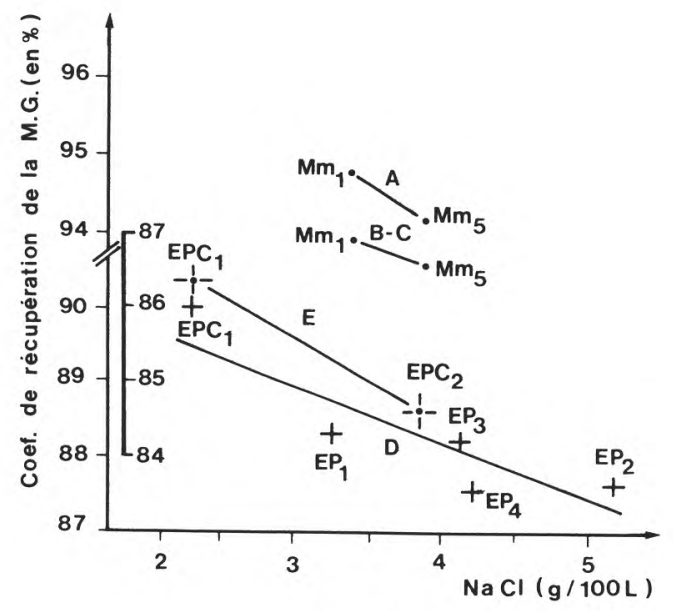

Fig. 9

Incidence de l'apport de $\mathrm{NaCl}$ par les préparations coagulantes sur les coefficients de récupération de la matière grasse.

Effect of $\mathrm{NaCl}$ contents of the different coagulant preparations on milk fat recovery coefficient. 
b) L'apport de $\mathrm{P}_{2} \mathrm{O}_{5}$ varie entre 0,02 et $0,25 \mathrm{~g}$ pour 1001 de lait.

Une étude antérieure (Deschamps, 1983) avait permis d'étudier l'influence de l'apport de $\mathrm{P}_{2} \mathrm{O}_{5}$ à partir de coagulants expérimentaux. Les résultats obtenus lors de nos fabrications sont concordants : une augmentation de 0,02 à $0,25 \mathrm{~g}$ pour $100 \mathrm{l}$ de lait de $\mathrm{P}_{2} \mathrm{O}_{5}$ provoque une organisation plus lente, mais des fermetés pour un temps de durcissement donné plus importantes des caillés.

Le rôle joué par chaque élément du «support » dans le processus d'organisation du coagulum n'a pu être déterminé précisément. Il semble que les modifications observées soient le résultat d'une action combinée $\mathrm{NaCl}-\mathrm{P}_{2} \mathrm{O}_{5}$.

En résumé, il apparaît que les coagulants pauvres en sel $(\mathrm{NaCl})$, riches en phosphore $\left(\mathrm{P}_{2} \mathrm{O}_{5}\right)$ et riches en azote non ammoniacal, donnent les meilleurs résultats et conduisent aux rendements fromagers les plus élevés avec les technologies mises en œuvre (technologies à caractère présure).

Le choix d'un coagulant ne doit donc pas se limiter à l'enzyme elle-même, ni à son activité, le "support " doit également être pris en compte.

La quantité de «support» apportée varie, en fonction inverse de la concentration en enzyme de la préparation coagulante (tabl. 12) :

- lorsqu'une importante organisation du gel est recherchée (cas des technologies présures par exemple), le choix se portera vers les préparations concentrées (EPC) afin de minimiser l'apport de «support" et donc de réduire les effets combinés $\mathrm{NaCl}-\mathrm{P}_{2} \mathrm{O}_{5}$. Il en résulte une organisation du caillé à la fois plus lente, ce qui laisse plus de latitude et de temps pour le décaillage, et plus poussée (caillé plus ferme), ce qui permet de mieux égoutter le caillé ;

- à l'inverse, lorsqu'une importante déminéralisation du caillé est recherchée : cas des technologies lactiques par exemple, ou avec des laits à fort pouvoir tampon (laits riches en matières azotées, ou enrichis par ultrafiltration ou en caséinate de calcium), on aura tout intérêt à utiliser des préparations coagulantes faiblement concentrées qui entraîneront un apport important de support $\left(\mathrm{NaCl}, \mathrm{P}_{2} \mathrm{O}_{5}, \mathrm{~N}\right.$. non ammoniacal).

Reçu le 10 juin 1986. Accepté pour publication le 20 décembre 1986.

\section{Remerciements}

Les auteurs tiennent à remercier tous ceux qui ont contribué à ce travail et notamment Monsieur J.-L. MaUBoIs pour l'intérêt qu'il a porté à cette étude. 


\section{Références bibliographiques}

Alais C., 1975. Science du Lait. Principe des techniques laitières. $3^{e}$ éd. SEP, Paris, 637.

Ben Slimane S., 1986. Variations de l'activité de la plasmine et du plasminogène dans le lait de vaches Montbéliardes et dans les fromages de type Comté. Thèse de Doctorat, Université de Besançon.

Brule G., Lenoir J., 1984. La coagulation du lait. In : Le Fromage, Eck A. ed., Technique et Documentation. Lavoisier, Paris, 1-21.

Charpentier A., Volhard J., 1874. Dosage du chlorure de sodium. J. Prak. Chem., 117, 217-224.

Desmazeaud M., Hermier J.H., 1972. Isolement et détermination de la composition qualitative de peptides issus de la caséine, stimulant la croissance de «Streptococcus thermophilus », Eur. J. Biochem, 28, 190-198.

Deschamps P., 1983. Etude biochimique et aptitudes technologiques des présures d'origine animale. Mémoire fin études ENITA. Dijon.

Duval L., 1963. Dosage du phosphore. Chim. anal., 45, 237-250.

Fleury P., Eberrhard R., 1958. Dosage de l'azote ammoniacal Ann. Pharm. Fr., 16, 465-482.

Garnier J., Mocquot G., Ribadeau Dumas B., Maubois J.L., 1968. Coagulation du lait par la présure. Aspects scientifiques et technologiques. Ann. Nutr. Aliment., 22, B 495-B 552.

Granday G., 1980. Composition de coagulant pour fromagerie comprenant au moins une enzyme fongique coagulante et produit fromager ainsi obtenu. Brevet français $\mathrm{n}^{\circ} 80.24420$.

Green M.L., 1977. Review of the progress of Dairy Science : milk coagulant. J. Dairy Res., 44, 159-188.

Institut technique du gruyère, 1975. La recuite : milieu de culture des lactobacilles. Etude ZS/74/ BE.

Institut technique du gruyère, 1978-1980. Notation de l'emmental. Document du 20 nov. 1978 et du 9 sept. 1980.

Institut technique du gruyère, 1984. Mesure du temps de coagulation et de la fermeté du caillé. Etude comparative de 3 appareils : le Formagraph, le Thromboelastograph et le Gélograph. Publication I.T.G.

Institut technique du gruyère, 1985. La mesure du point de congélation dans les fromages à pâte cuite. Etude ZS/74/BE.

Maubois J.L., Mocquot G., 1967. Comment ramener à la même teneur en substance sèche, des fabrications de fromages en vue de comparer les rendements spécifiques du lait en fromage. Rev. Lait. Fr., (239), 15-18.

Mietton B., 1981. L’emballage et le stockage des pâtes molles - Résultats expérimentaux sur carré de l'Est. Rev. ENIL, (62), 19-35.

Mietton B., Quiblier J.P., Olsson A., 1982. Etude comparative de différentes préparations coagulantes usuelles ou enrichies en azote, en technologie pâte molle. Rev. ENIL, $1^{\text {te }}$ partie, (73), $9-13 ; 2^{\mathrm{e}}$ partie, (74), 35-43.

Perrod J.L., 1984. Caractéristiques rhéologiques de quelques préparations coagulantes. Etude sur Gélograph. Résultats non publiés.

QUiblier J.P., 1982. Contribution à l'étude biochimique d'une préparation enzymatique coagulante " Mucagel ». Mémoire fin études ENITA, Dijon.

Ramet J.L., Alais C., Weber F., 1969. Etude d'un enzyme coagulant microbien dérivé d'» Endothia parasitica ». Lait, (481-482), 40-52.

SCRIBAN R., 1984. Biotechnologie, Technique et Documentation. Lavoisier, Paris, 346. 